\title{
OXA-48-like carbapenemases producing Enterobacteriaceae in different niches
}

\author{
Assia Mairi $^{1,2} \cdot$ Alix Pantel $^{2,3} \cdot$ Albert Sotto $^{2} \cdot$ Jean-Philippe Lavigne $^{2,3} \cdot$ Aziz Touati $^{1}$
}

Received: 5 September 2017 / Accepted: 15 September 2017 / Published online: 8 October 2017

(C) Springer-Verlag GmbH Germany 2017

\begin{abstract}
The emergence of carbapenem-resistant enterobacterial species poses a serious threat to public health worldwide. OXA-48-type carbapenem-hydrolyzing class D $\beta$-lactamases are widely distributed among Enterobacteriaceae, with significant geographical differences. To date, 11 OXA-48-like variants have been identified, with classical OXA-48 being the most widespread. These enzymes show high-level hydrolytic activity against penicillins and low-level hydrolysis towards carbapenems. Since the first description of the OXA-48 carbapenemase in Turkey, bacterial strains producing the enzyme have been extensively reported in nosocomial and community outbreaks in many parts of the word, particularly in the Mediterranean area and European countries. The rapid spread of Enterobacteriaceae producing OXA-48-like enzymes in different ecosystems has become a serious issue recently. The number of reservoirs for such organisms is increasing, not only in hospitals, but also in the community, among animals (e.g., livestock, companion animals, and wildlife) and in the environment. This review aims to summarize the main characteristics of the OXA-48-
\end{abstract}

Electronic supplementary material The online version of this article (https://doi.org/10.1007/s10096-017-3112-7) contains supplementary material, which is available to authorized users.

Jean-Philippe Lavigne

jean.philippe.lavigne@chu-nimes.fr

1 Laboratoire d'Ecologie Microbienne, FSNV, Université de Bejaia, 06000 Bejaia, Algeria

2 Institut National de la Santé et de la Recherche Médicale, U1047, Université Montpellier, UFR de Médecine, 186 Chemin du Carreau de Lanes, CS83021, 30908 Nîmes, France

3 Department of Microbiology, University Hospital of Nîmes, Nîmes, France type carbapenemases, covering genetic and enzymatic traits, their epidemiology, clonality and associated genes, correlation with extended-spectrum $\beta$-lactamases (ESBLs) or plasmidic AmpC (pAmpC) in different bacterial species worldwide.

Keywords Carbapenemase Enterobacteriaceae Environment · Niches · OXA-48-like · Persistence

\section{$\beta$-lactam resistance and enterobacteria}

Enterobacteriaceae are opportunistic pathogens that are found as commensals in the intestinal tract of humans and animals, and are frequently associated with a variety of community and hospital-acquired infections [1]. $\beta$-lactams including penicillins, cephalosporins, aztreonam, and carbapenems are the principal therapeutic choices for the treatment of Enterobacteriaceae infections, and constitute approximately $60 \%$ of all clinically used antibiotics in human and veterinary medicine [2]. Consumption of antibiotics has risen over recent years in many countries [3], both in humans and animals, and has contributed to an increase of antibiotic residues in the environment. The presence of antibiotic residues in the environment and many if not all reservoirs of life exerts selective pressure leading to the emergence and dissemination of bacterial resistance [4].

Gram-negative bacteria, including Enterobacteriaceae, have developed multiple strategies to overcome antibiotic effects by employing several resistance mechanisms (alteration of the antibiotics by production of enzymes, modification of the bacterial envelope by decreasing the porin production or increasing the expression of efflux pump systems, changes in cellular permeability of antibiotics, and reduction of the antibiotic affinity by the modification of drug targets) [5]. These 
phenomena are encountered in various clinical isolates showing a multidrug-resistant (MDR) phenotype [6].

Production of $\beta$-lactamases constitutes the principal mechanism of bacterial resistance to $\beta$-lactam antibiotics among enterobacteria [7]. The first described $\beta$-lactamase in Gram-negative bacteria was TEM-1 (for TEMONEIRA) isolated from Escherichia coli in 1963 in Greece [8]. In turn, the pharmaceutical industry developed novel $\beta$-lactam compounds resistant to hydrolysis by large spectrum $\beta$-lactamases (TEM-1/2 and SHV-1) that were popularly known as third-generation cephalosporins (3GCs). The further selection of resistant mutants by overproduction of chromosomal AmpC through acquisition of either extended-spectrum $\beta$-lactamases (ESBLs) or plasmidic AmpC (pAmpC) has compromised the use of $3 \mathrm{GCs}$ for the treatment of serious infections caused by Gram-negative bacteria [9]. Among the ESBLs genes described, blaTEM genes, blaSHV genes, and particularly blaCTX-M genes are the most frequently reported [10]. In parallel, pAmpC, including bla $\mathrm{CMY}$ and blaDHA, have increased over the last decade [11], but are less frequently reported compared to ESBLs genes [12].

To counter this situation, carbapenems were developed and introduced into the therapeutic arsenal through the 1990s [8]. These molecules are extremely stable to degradation by ESBLs and $\mathrm{pAmpC}$, and are used to treat severe infections caused by ESBLs and pAmpC producers [13]. In 1988, the first plasmidic carbapenemase, IMI-1, was reported in Japanese Pseudomonas aeruginosa isolate [14]. However, the first carbapenemase producer in Enterobacteriaceae (NmcA) was not identified until 1993 in a clinical isolate of Enterobacter cloacae [15]. This class A carbapenemase was chromosomally encoded, but has rarely been reported since. Subsequently, numerous carbapenemase-producing Enterobacteriaceae (CPE) have been identified [16]. Nowadays, carbapenemases described in Enterobacteriaceae are divided into three classes according to the Ambler classification: (i) class A $\beta$-lactamases (Klebsiella pneumoniae carbapenemase (KPC), NmcA, IMI, Sme, and GES-type which are inhibited by clavulanic acid or boronic acid, (ii) class B metallo- $\beta$-lactamases [New Delhi metallo- $\beta$ lactamase (NDM), imipenemase (IMP), and Verona integron-encoded metallo- $\beta$-lactamase (VIM)] hydrolyzing all $\beta$-lactams except aztreonam and inhibited by chelating agents such as EDTA and dipicolinic acid, and (iii) class D $\beta$-lactamases (oxacillinases), including OXA-48-like enzymes hydrolyzing carbapenems but only weakly (or not) hydrolyzing cephalosporins and not inhibited by classical inhibitors [17, 18]. The carbapenemase genes in Enterobacteriaceae have been shown to be associated with mobile genetic elements such as plasmids or transposons, thereby facilitating their dissemination into the community and the environment [19].
In recent years, an increasing number of studies that include OXA-48-like carbapenemase-producing Enterobacteriaceae have been published including humans and veterinary practices, animal production, food chain, companion animals, wild animals, agriculture, and environments across different countries.

\section{Biochemical and genetic properties of OXA-48-like}

The OXA-48 carbapenemase was first reported in a Klebsiella pneumoniae isolate from a 54-year-old man with a urinary tract infection and skin burns from Istanbul (Turkey) in 2001 [20]. Since then, it has been identified as a source of nosocomial outbreaks in this country [21].

Analysis of the enzyme kinetics of OXA-48 showed that it has high-level hydrolytic activity against penicillins and lowlevel hydrolysis towards carbapenems [22]. Among carbapenems, OXA-48 has a low level of hydrolytic activity for both imipenem and meropenem compared to ertapenem, which represents the best substrate for this enzyme [23].

Since the discovery of OXA-48, several variants have emerged including OXA-162 (single substitution at Thr213Ala), identified from $K$. pneumoniae isolates in Turkey [24], OXA-163 (single substitution at Ser212Asp and four deletions at Arg214, Ile215, Glu216, and Pro217), identified in K. pneumoniae and Enterobacter cloacae isolates in Argentina [25], OXA-181 (four substitutions at Thr104Ala, Asn110Asp, Glu168Gln, and Ser171Ala), identified from a K. pneumoniae isolate in India [26], OXA-204 (two substitutions at Gln98His Thr99Arg), identified in K. pneumoniae isolates in patients having a link with North Africa [27], OXA-232 (single substitution at Arg214Ser), identified in France from a K. pneumoniae isolate recovered from a patient who had been transferred from India to Mauritius [28], OXA244 (single substitution at Arg214Gly) and OXA-245 (single substitution at Glu125Tyr), collected from $K$. pneumoniae isolates in Spain [29], OXA-247 (two substitutions at Tyr211Ser and Asp212Asn), identified from a $K$. pneumoniae isolate recovered in Argentina [30], OXA-370 (single substitution at Gly220Glu), reported from an Enterobacter hormaechei isolate in Brazil [31], and OXA-405 (four deletions at Thr213 to Glu216), identified from Serratia marcescens isolates in France [32]. These variants differ from OXA-48 by one to five amino acid substitutions and/or by a four-aminoacid deletion, which results in a modified $\beta$-lactam hydrolysis spectrum (Table 1, Fig. S1) [18].

While OXA-163 appears to be a very poor hydrolyser of the carbapenems, OXA-181 and OXA-232 are broadly similar to OXA-48 in their activity; OXA-232 has a reduced ability to hydrolyze carbapenems but possesses higher hydrolysis activity against penicillins [25, 28]. Interestingly, OXA-163 and OXA-405 have marginal carbapenem hydrolytic activity, but 
Table 1 Variants of OXA-48-like enzyme and degree of homology (\%)

\begin{tabular}{|c|c|c|c|c|c|c|c|c|c|c|c|c|}
\hline $\begin{array}{l}\text { OXA-48-like } \\
\text { variants }\end{array}$ & $\begin{array}{l}\text { OXA- } \\
48\end{array}$ & $\begin{array}{l}\text { OXA- } \\
162\end{array}$ & $\begin{array}{l}\text { OXA- } \\
163\end{array}$ & $\begin{array}{l}\text { OXA- } \\
181\end{array}$ & $\begin{array}{l}\text { OXA- } \\
199\end{array}$ & $\begin{array}{l}\text { OXA- } \\
204\end{array}$ & $\begin{array}{l}\text { OXA- } \\
232^{\mathrm{a}}\end{array}$ & $\begin{array}{l}\text { OXA- } \\
244\end{array}$ & $\begin{array}{l}\text { OXA- } \\
245\end{array}$ & $\begin{array}{l}\text { OXA- } \\
247^{\mathrm{b}}\end{array}$ & $\begin{array}{l}\text { OXA- } \\
370\end{array}$ & $\begin{array}{l}\text { OXA- } \\
405\end{array}$ \\
\hline OXA-48 & 100 & 99 & 98 & 98 & 99 & 99 & 98 & 99 & 99 & 98 & 99 & 98 \\
\hline OXA-162 & 99 & 100 & 98 & 98 & 98 & 99 & 98 & 99 & 99 & 97 & 99 & 98 \\
\hline OXA-163 & 98 & 98 & 100 & 98 & 98 & 98 & 98 & 98 & 98 & 99 & 98 & 99 \\
\hline OXA-181 & 98 & 98 & 98 & 100 & 98 & 98 & 99 & 98 & 98 & 98 & 98 & 98 \\
\hline OXA-199 & 99 & 98 & 98 & 98 & 100 & 99 & 99 & 99 & 99 & 99 & 99 & 99 \\
\hline OXA-204 & 99 & 99 & 98 & 98 & 99 & 100 & 99 & 99 & 99 & 99 & 99 & 99 \\
\hline OXA- $232^{\mathrm{a}}$ & 98 & 98 & 98 & 99 & 99 & 99 & 100 & 98 & 98 & 98 & 98 & 98 \\
\hline OXA-244 & 99 & 99 & 98 & 98 & 99 & 99 & 98 & 100 & 99 & 99 & 99 & 99 \\
\hline OXA-245 & 99 & 99 & 98 & 98 & 99 & 99 & 98 & 99 & 100 & 99 & 99 & 99 \\
\hline OXA- $247^{b}$ & 98 & 97 & 99 & 98 & 99 & 99 & 98 & 99 & 99 & 100 & 98 & 99 \\
\hline OXA-370 & 99 & 99 & 98 & 98 & 99 & 99 & 98 & 99 & 99 & 98 & 100 & 98 \\
\hline OXA-405 & 98 & 98 & 99 & 98 & 99 & 99 & 98 & 98 & 98 & 98 & 98 & 100 \\
\hline
\end{tabular}

OXA-48-like variants deposited and compared percentages of identity in NCBI website (http://www.ncbi.nlm.nih.gov/pubmed/)

${ }^{a}$ OXA-232: A mutant derivative of OXA-181, not derived from OXA-48

${ }^{\mathrm{b}}$ OXA-247: Two amino acid derivatives of OXA-163, not originating from OXA-48

showed capacity to hydrolyze ceftazidime and aztreonam, and they share an increased ability to hydrolyze cefotaxime and cefepime over OXA-48, making these enzymes more similar to ESBL enzymes than to carbapenemase [25, 33].

It has been proposed that the progenitor gene of OXA48 is a property of Shewanella spp., a waterborne bacterium. Shewanella oneidensis strain MR-1 has been found to naturally harbor the blaOXA-54 gene, which is closely related to the blaOXA-48 gene [34]. Shewanella xiamenensis is a recently validated species that has been reported in different parts of the world [35]. The blaOXA181 gene seems likely to have originated from S. xiamenensis [36]. In addition, several other variants of blaOXA-48 genes have been identified in S. xiamenensis strains including blaOXA-48, blaOXA199 [37], and blaOXA-204 [38]. Mobile genetic elements might have been involved in the mobilization of Shewanella chromosomal carbapenemases to plasmids, which have then spread to other bacterial species [39].

The emergence of the OXA-48 enzyme is mediated by the rapid spread of a broad host-range conjugative plasmid harboring the blaOXA-48 gene located within a composite transposon, namely $T n 1999$, that flanks the carbapenemase gene and cooperates in mobilizing an intervening DNA segment $[40,41]$. Sequence analysis of plasmid pOXA-48 demonstrated that the blaOXA-48 gene is flanked by two copies of IS1999 [40]. In addition, the blaOXA-48 gene could be inserted into the second variant $T n 1999.2$ which was identified in clinical K. pneumoniae isolates from Turkey. The $T n 1999.2$ differs to $T n 1999$ by the insertion of $I S 1 \mathrm{R}$ within the IS1999 located upstream of blaOXA-48. The Tn1999.3 has been identified in an E. coli isolate from Italy, with a second copy of IS $1 \mathrm{R}$ located downstream of blaOXA-48 $[21,42]$. Recently, the blaOXA-48 gene was identified as a part of a novel transposon variant, named $T n 1999.4$. This transposon has been recovered in E. coli and E. cloacae, composed of $T n 1999.2$ truncated by another transposon, $T n 2015$ (Fig. 1). This latter is comprised of ISEcp1, blaCTX-M-15, and a truncated $\operatorname{Tn} 2$-type transposase gene [43]. Finally, the blaOXA-48 gene was found in $T n 1999.5$, a novel variant of the $T n 1999.2$ transposon in which the lys $R$ gene encoding a transcriptional regulator was truncated by the ISKpn19 element [44].

IS1999 was initially reported in clinical Pseudomonas aeruginosa isolates from Thailand [45]. In these strains, IS1999 was inserted into an integron-specific recombination site, attI1, upstream of the integron-borne blaVEB-1 gene that encodes an ESBL [40].

The blaOXA-48-like genes are most frequently observed in the IncL/M plasmids which carry no additional resistance genes and are $60-70 \mathrm{~Kb}$ [46]. The IncL/M plasmids are currently one of the six major resistance plasmid families identified in clinically relevant Enterobacteriaceae, and are now commonly identified among environmental and clinical isolates, together with several IncF variants, IncA/C, IncI, IncHI2, and IncX3 and ColE-like replicons [47]. The high transfer efficiency of the epidemic IncL/M plasmid to any enterobacterial species is the reason proposed for the successful spread of blaOXA-48 [48].

A chromosomal location of blaOXA-48 was recently reported by Turton et al. [49]. Two E. coli isolates carrying a chromosomally integrated blaOXA-48 shared a similar arrangement, with a plasmid fragment containing blaOXA-48 flanked by $I S 1 \mathrm{R}$ elements integrated into the chromosome, 


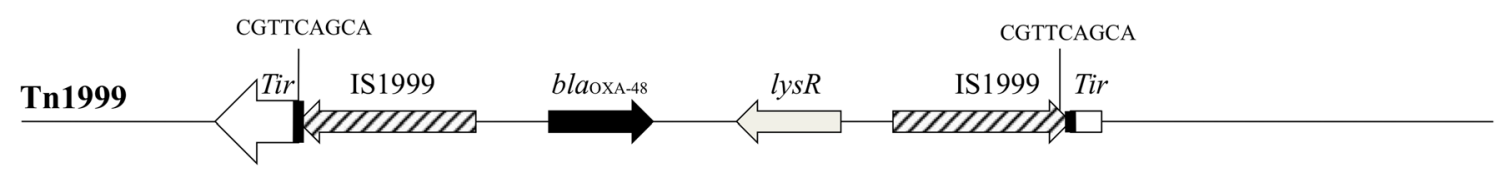

CGTTCAGCA

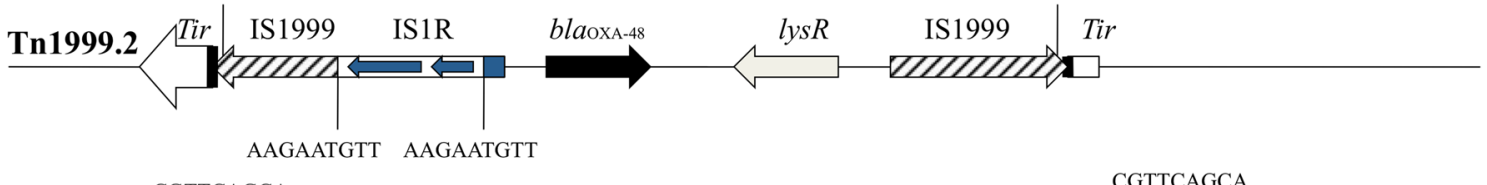
CGTTCAGCA
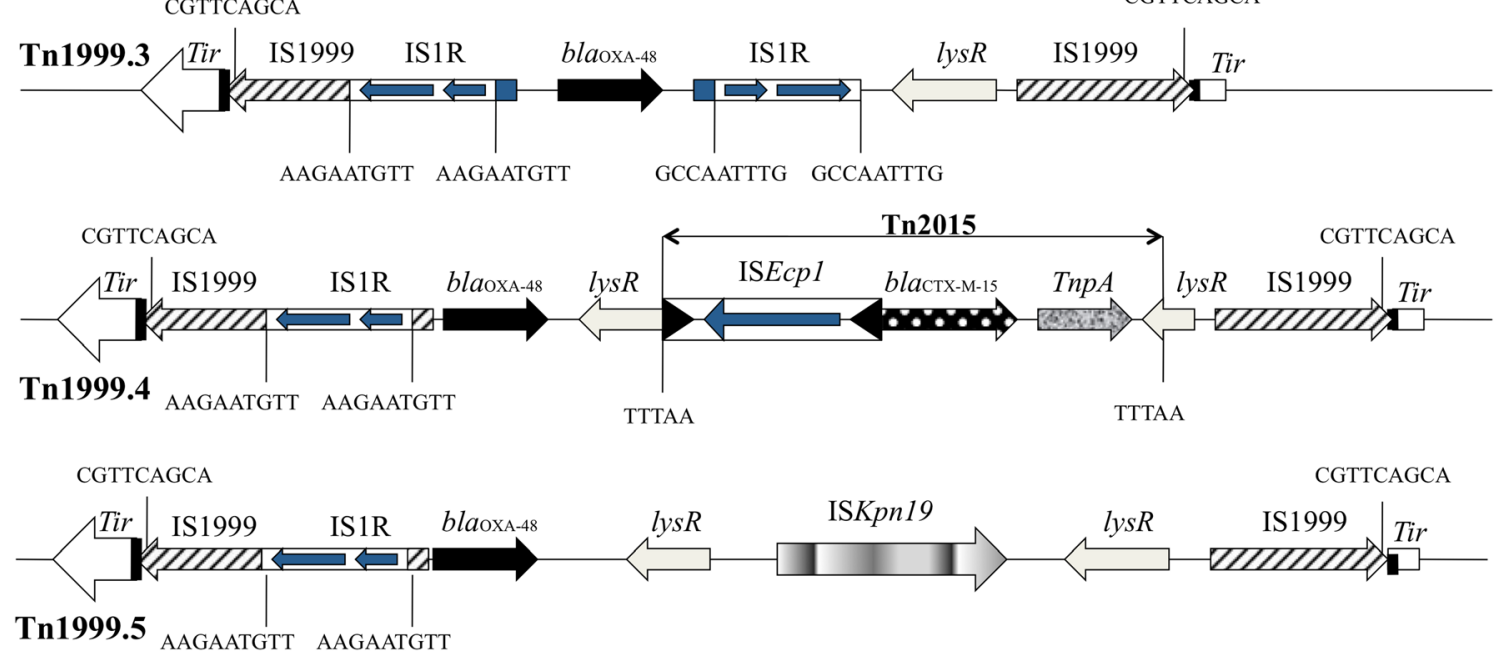

Fig. 1 Genetic environments of the blaOXA-48-bearing Tn1999-like transposon structures in Enterobacteriaceae isolates

although the length of the plasmid fragment and the insertion site differed between the two isolates. Beyrouthy et al. showed that the insertion of the blaOXA-48 gene into the E. coli chromosome is not a rare event and may occur at different sites, and that the DNA fragments harboring the blaOXA-48 gene originated in a pOXA-48a-type plasmid [41]. In another study, Beyrouthy et al. indicated that plasticity of the OXA-48 genetic environment was mediated by ISIR insertion sequences. The insertion sequences can induce the transfer of the OXA48 encoding gene into $E$. coli chromosomes and thereby promote its persistence and expression at low levels [50]. The same was also described for the blaOXA-181 gene in K. pneumoniae [51].

\section{OXA-48-like and associated genes}

\section{ESBL and pAmpC}

A significant proportion of OXA-48-like producers have been found to co-express ESBLs and pAmpC genes on additional plasmids (Fig. 2). Several studies describing ESBLs in association with OXA-48 in Enterobacteriaceae have been reported, including blaTEM, blaSHV, and blaCTX-M-like genes. The association with blaCTX-M-like gene was the most frequently detected, including CTX-M-1 [52], CTX-M-8 [53],
CTX-M-9 [52], CTX-M-14 [54], CTX-M-15 [55], CTX-M24 [56], CTX-M-27 [57], and CTX-M-123 variants [58].

Among SHV enzymes, different variants have been identified: SHV-11 and SHV-12 have been reported in E. coli and $K$. pneumoniae in many European countries and in the Mediterranean area; SHV-27 was detected in one $K$. pneumoniae isolate in Morocco [59]; SHV-28 was identified in $K$. pneumoniae from Germany, India, Kuwait, Morocco, and Tunisia [60-64]; SHV-85 and SHV-133 were found in one isolate of $K$. pneumoniae in Algeria [65]; and SHV-134 was described in Spain [66].

The TEM-type ESBL determinants were also reported in OXA-48-producing isolates: TEM-5 in E. coli from USA [58]; TEM-31 in K. pneumoniae from Taiwan; and TEM198 in E. cloacae from Algeria [67, 68].

Furthermore, some studies reported co-production both of OXA-48-like and pAmpC genes. CMY-2 has been recovered in K. pneumoniae and E. coli from Algeria, Denmark, Germany, India, Tunisia, and the USA [58, 64, 69-72]; CMY-4 in K. pneumoniae isolates from Singapore, Thailand and Tunisia [54, 73-76]; CMY-6 in a single $K$. pneumoniae isolate from India [77]; and DHA-1 in K. pneumoniae from Greece, Morocco, Sri Lanka, Thailand, and Tunisia [33, 59, $62,71,78]$.

In addition, VEB- 8 was identified in a single $K$. pneumoniae isolate from Tunisia that co-produced the CMY-2 and CTX-M-15 enzymes [79]. 


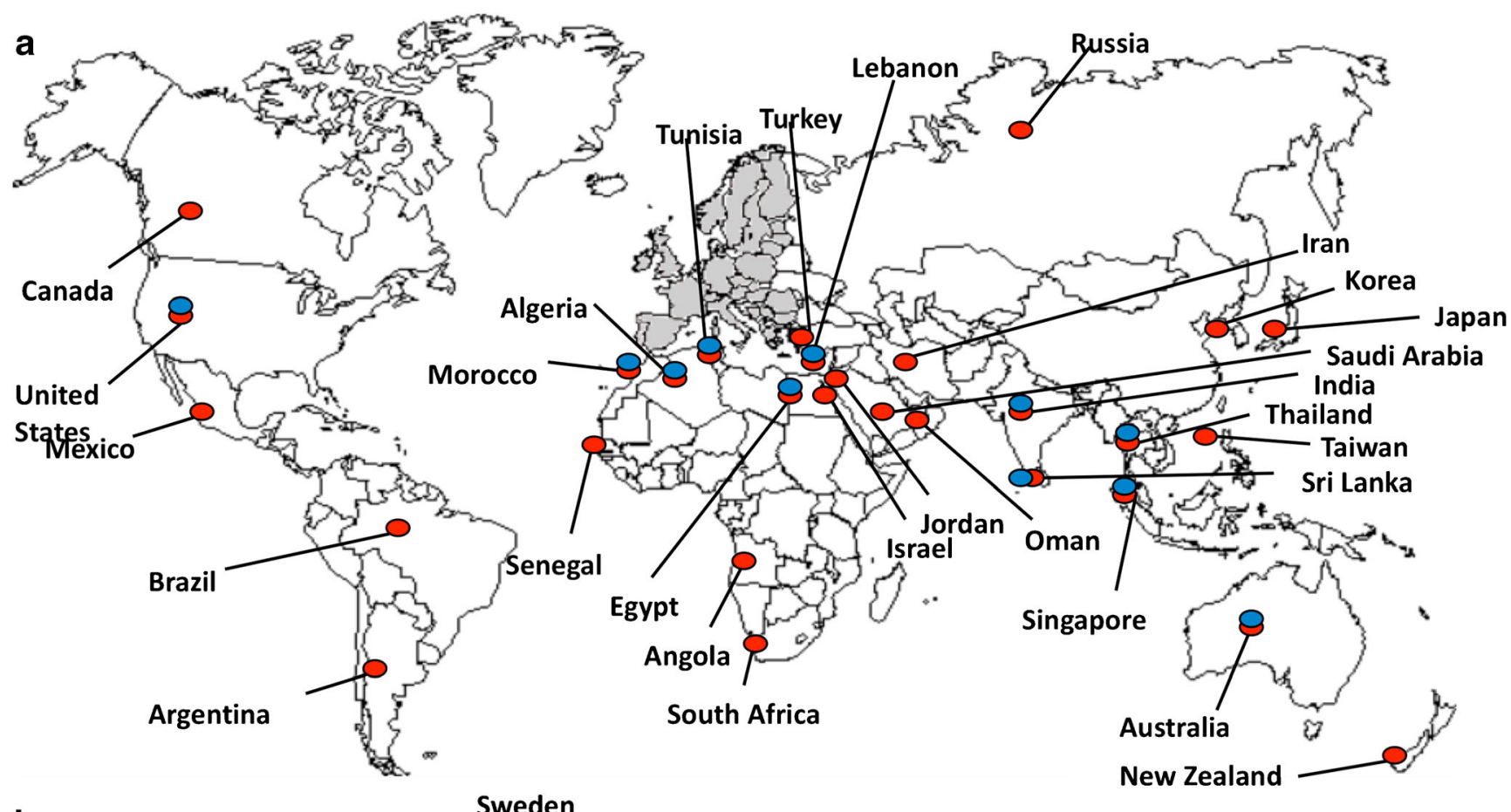

b

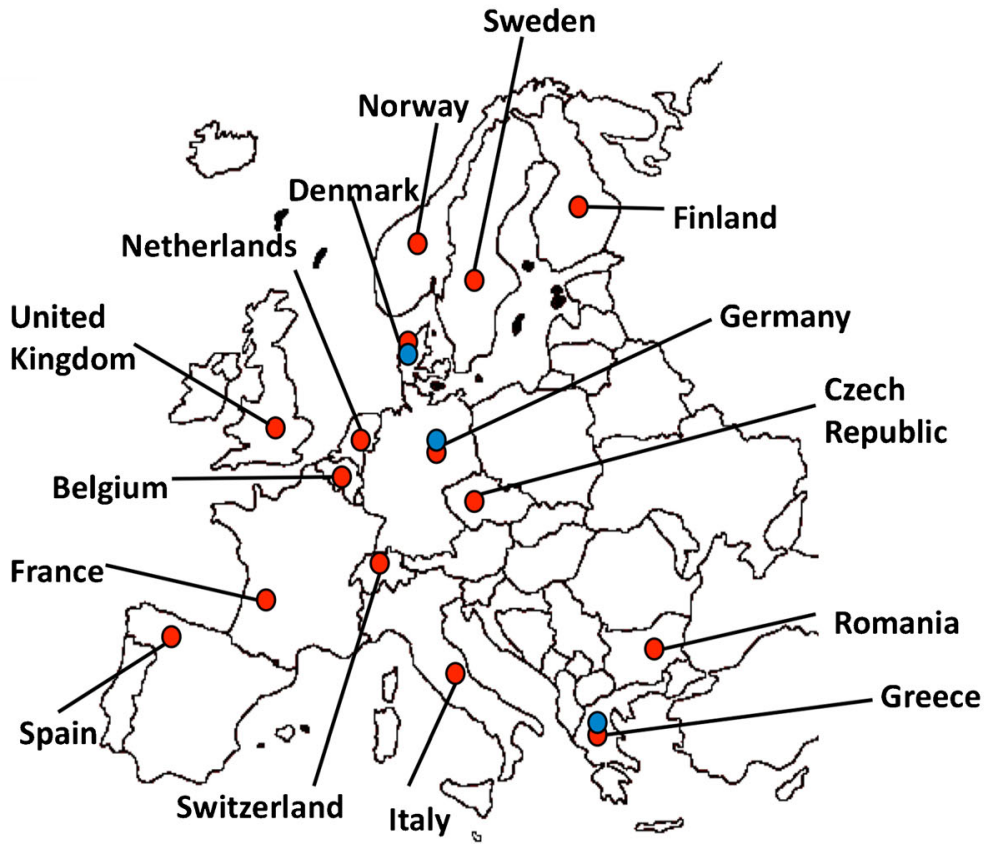

ESBLs enterobacterial producers

pAmpC enterobacterial producers

Fig. 2 Distribution of OXA-48-like-producers co-producing ESBLs and pAmpC genes. (A) Global distribution outside of Europe; (B) European distribution

Association with other carbapenemase-encoding genes

Several studies have reported the association between OXA-48-like and NDM-1 in enterobacterial species from different countries [60, 78, 80-92]: NDM-5 in K. pneumoniae from South Korea and the USA [51, 93]; NDM-7 in K. pneumoniae from India, Iran, and Spain [77, 92, 94]; KPC-2 in K. pneumoniae from Belgium and Malaysia [83, 95]; VIM-1 in different enterobacteria from Egypt and France [84, 87, 96]; VIM-5 in
K. pneumoniae from Turkey [82]; and IMP-1 in E. coli from India [88].

Additional co-located resistance genes

Other plasmidic resistance genes were also associated with OXA-48-like-production in enterobacteria.

The plasmid-mediated resistance markers to quinolones (PMQR) qnrA, qnrB, qnrS and $a a c\left(6^{\prime}\right)-I b-c r$ have usually been associated with OXA-48-producers in clinical 
isolates. These genes have been described from Germany in E. cloacae [97], from Morocco in K. pneumoniae and E. coli [61], from North America in K. pneumoniae [98], from Saudi Arabia in K. pneumoniae and E. coli [99], from Senegal in E. coli, E. cloacae, E. sakazakii, and K. pneumoniae [100], from Tunisia in Providencia rettgeri [101], and from Turkey in C. freundii [102]. The associations between OXA-48-producers and PMQR markers were not exclusively found in humans, with Stolle et al. reporting $q n r B$ and $a a c\left(6^{\prime}\right)-I b-c r$ associated with blaCTXM-1, blaSHV-12, blaTEM-1, blaOXA-2, blaCMY-2 genes, recovered in E. coli, and K. pneumoniae in German dogs [64].

An OXA-232-producing K. pneumoniae was reported in a clinical strain from India, including $\beta$-lactamases (CTX-M15, SHV-28 and OXA-1-like), aminoglycoside resistance genes ( $a r m A$ and $a a c C$ ), and fluoroquinolone resistance determinants ( $q n r B$ and $\left.a a c\left(6^{\prime}\right)-I b-c r\right)$ [60]. Additionally, OXA181-producing $K$. pneumoniae and $E$. coli were associated with $q n r S$ or $q n r B$ and $a a c\left(6^{\prime}\right)-I b-c r$ in Australia, Canada, and Thailand [71, 76, 103].

Finally, plasmid-mediated $16 \mathrm{~S}$ rRNA methylase aminoglycoside resistance determinants $a r m A, r m t B, r m t C$, and $r m t F$ were also combined with OXA-48-like producers. They were observed in Australia, Greece, India, Morocco, North America, and Thailand [60, 76, 80, 98, 103, 104]. In addition, aac(3)-II determinant were recovered in K. pneumoniae in Morocco [61].

\section{Epidemiology of OXA-48-like from human sources}

Different studies have been published reporting the emergence and dispersal of OXA-48 genes and the bacterial strains harboring such genes in a worldwide fashion. A search in PubMed using OXA-48 in humans as a keyword showed an increasing number of reports of OXA-48 producers for the period 2004 to 2017 (from two between 2004 and 2007 to 73 between 2016 and 2017). Although blaOXA-48-like genes have been most often found in $K$. pneumoniae, the plasmids harboring this resistance are now widespread in multiple species such as E. coli, Klebsiella oxytoca, E. cloacae, Enterobacter aerogenes, Enterobacter sakasakii, Citrobacter freundii, Citrobacter koseri, Citrobacter braakii, Providencia rettgeri, Serratia marcescens, Salmonella enterica, Morganella morganii, and Raoultella planticola [21, 41, 61, 84, 97, 100, 105-108]. Figure S2 shows the distribution of OXA-48producing Enterobacteriaceae species over the period 2004-2017. The clonal distribution of OXA-48 carbapenemase-producing Enterobacteriaceae isolates is reported in Fig. 3.

\section{Worldwide dissemination of OXA-48-like enzymes}

Since the first description of the OXA-48 carbapenemase in Turkey, the enzyme has been extensively reported as a source of nosocomial and community outbreaks in many parts of the world, particularly in the Mediterranean area [109] (Fig. 4). It has been described in Algeria [65, 110-114], Argentina [98], Belgium [83, 85, 115-117], Bulgaria [118], China [119], Columbia [120], Croatia [121], the Czech Republic [44], Denmark [69, 122, 123], Egypt [87, 96], Finland [120], France [56, 84, 124-129], Germany [130, 131], Greece [104, 132], Hungary [133], India [88, 134], Iran [92, 135-137], Ireland [138, 139], Israel [140, 141], Italy [42, 142, 143], Jordan [144], Kuwait [63], Lebanon [41, 145-149], Libya [150, 151], Morocco [59, 61, 152, 153], the Netherlands [9, 154-157], Romania [158], Russia [159], Saudi Arabia [89, 160], Senegal [100], Singapore [161], South Africa [162], Spain [94, 100, 106, 163-169], Sultanate Oman [170], Sweden [171], Switzerland [172, 173], Taiwan [68], Thailand [71], Tunisia [62, 79, 81, 101, 174-178], Turkey [20, 55, 102, 179-183], Brazil [184], Poland [185], Malaysia [95], the UK [52, 186], and the USA [187].

The OXA-48 producers were reported from hospitalized patients with diverse infections including UTIs, wound infections, and bloodstream infections. Furthermore, fecal carriage represents an important problem and a high risk factor for infection [61].

\section{OXA-48-like isolates and multilocus sequence typing (ST)}

Among K. pneumoniae, blaOXA-48-like genes are found in multiple STs. However, some dominant clones, including ST101, ST395, ST405, ST11, ST14, and ST15, have successfully emerged. OXA-48-positive $K$. pneumoniae belonging to ST101 was the most commonly observed ST in the Mediterranean area [126, 188]. It has been implicated in different outbreaks in Morocco, Spain, and Tunisia [177, 189]. This clone has now spread widely and has been recovered from many countries including European countries (the Czech Republic, Denmark, France, Germany, Ireland, Italy, Romania, Sweden, the UK), Africa (Egypt, Algeria), South East Asia (Malaysia), and the Middle East (Israel, Kuwait) [42, 52, 95, 96, 113, 115, 123, 130, 138, 158, 171, 190, 191]. ST395 and ST405 have been widely described in European outbreaks (e.g., Belgium, France, and Spain) involving strains from North Africa [66, 117, 157, 188, 192]. ST11 has been reported in outbreaks in Spain and Tunisia [81, 168]. This ST is now found throughout Europe and also in South Africa [66, 117, 132]. ST14 was recently characterized as the most prevalent clone in the UK [193]. Finally, OXA-48 enzymes were found in 


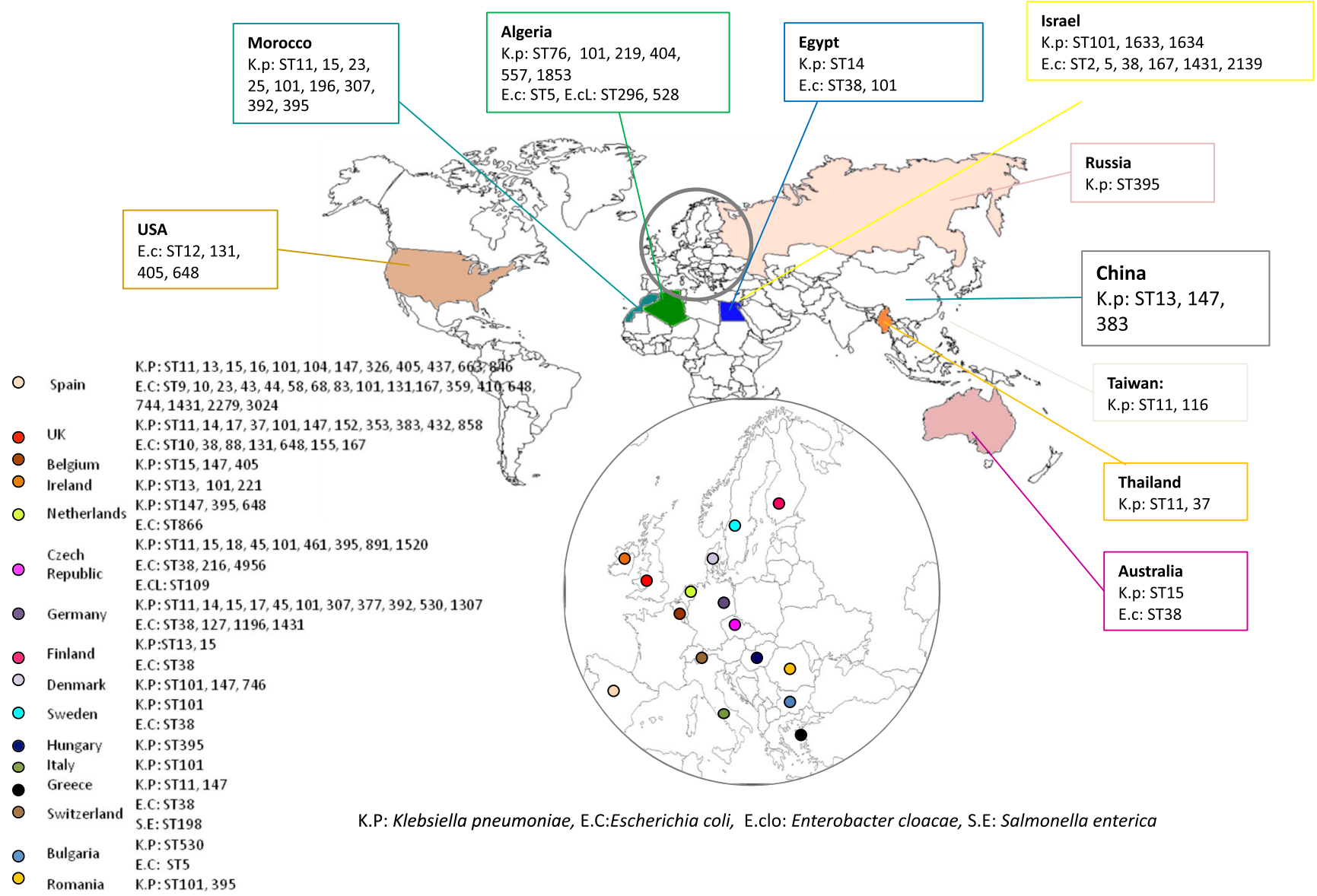

Fig. 3 Clonal distribution of OXA-48-like producing Enterobacteriaceae

ST15 which corresponds to a disseminated worldwide clone carrying ESBL and carbapenemases, notably in Europe [106, 126, 169, 194, 195].

This relatively high number of global clones illustrates the wide spread of OXA-48-producing $K$. pneumoniae in the Mediterranean area (Turkey, North Africa, and the Middle East) and in Europe. Interestingly, plasmids harboring the new variants such as blaOXA-181 were found in ST11, ST61, ST25, ST307, and ST709, or blaOXA232 in ST14, ST15, ST16, ST147, ST231, ST307, and ST395 [193]. Some differences in the repartition of the STs could be explained by their different geographical associations, with the new variants often arising on the Indian subcontinent.

The dissemination of OXA-48-producing E. coli is polyclonal, with multiple STs reported. In many studies, OXA-48-producing E. coli isolates have been described from patients after initial isolation of epidemic clone of $K$. pneumoniae, suggesting horizontal transfer of pOXA48a from $K$. pneumoniae to commensal $E$. coli in the intestine of the patient $[52,126,156,191,196]$. Of concern is the fact that the acquisition of OXA-48 by successful E. coli clones has already occurred. Indeed, the most prevalent OXA-48-producing E. coli in Spain belongs to ST131 (Warwick scheme) [197], which is known for its role in the global dissemination of ESBLs, especially CTX-M-15, including in community settings [198]. We could note that multiple ST schemes exist for this species (e.g., Warwick scheme, Pasteur scheme...). Similarly, ST38, another emerging global epidemic clone, is dominant in North Lebanon, in the UK, in Finland [41, 193, 194], and in France [56]. ST410 and ST88 were also identified [52, 193].

More recently, a chromosomal location of blaOXA-48 was reported from isolates in Egypt, France, Lebanon, Switzerland, and the UK [41, 52, 188]. Interestingly, chromosomal location of blaOXA-48 was mostly associated with E. coli ST38 co-harboring blaCTX-M-24 and blaTEM-1. This resistance and the ST are not only found among humans but also in fowl [199].

Since the development of the Enterobacter cloacae MLST scheme is recent, very few data are available for this species. The most prevalent OXA-48-positive clones belong to ST89 (in Poland) [185], ST108 (in the UK) [193], ST114 (in the South of France, personal data), and ST296 (in Algeria) [111]. 

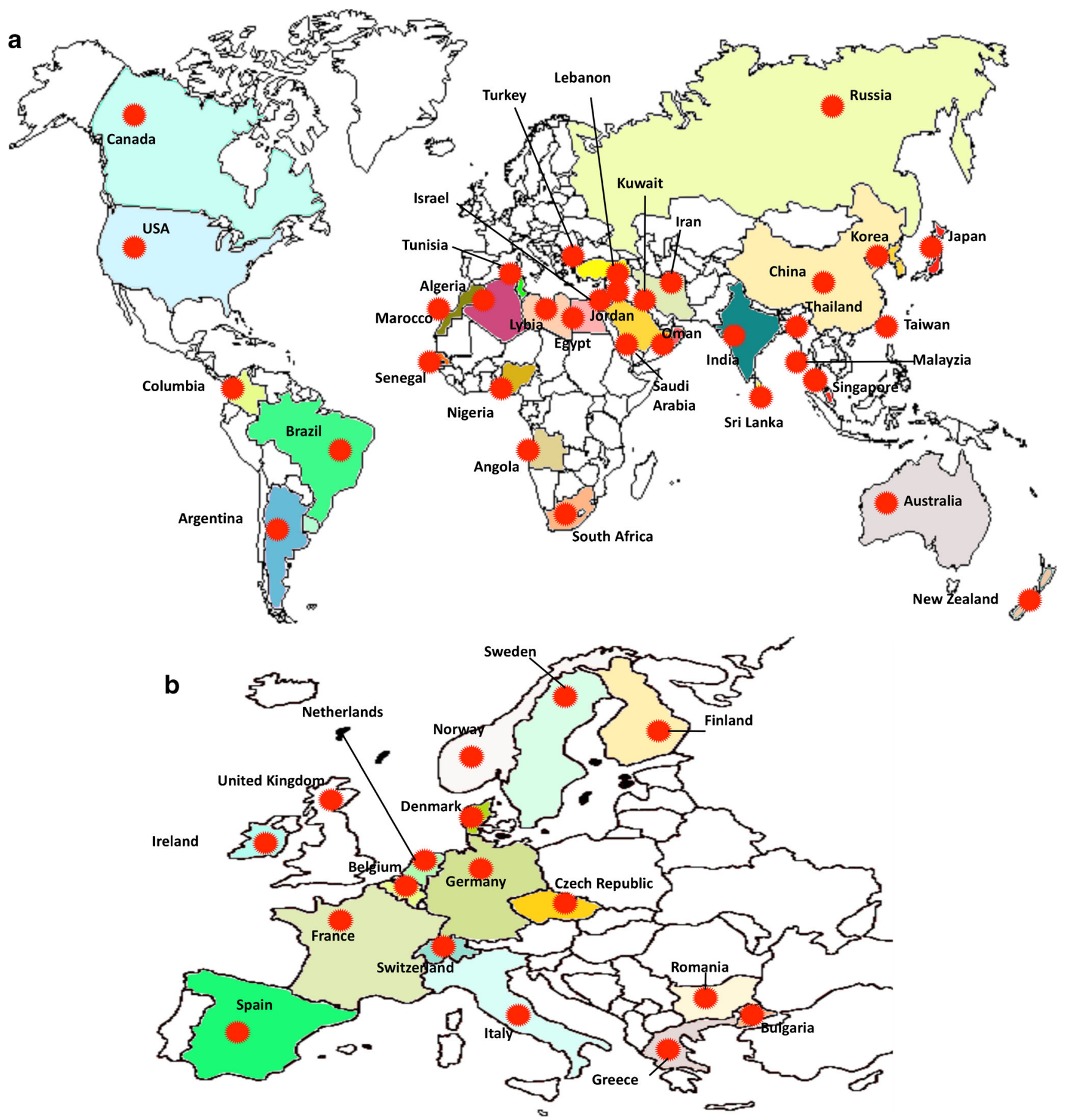

Fig. 4 Worldwide dissemination of OXA-48-like producers

\section{Risk factors of OXA-48-like acquisition/carriage}

There is a paucity of data with regard to risk factors predisposing to gut colonization with OXA-48-like. The gastrointestinal tract represents an important reservoir for these strains. The main risk factors identified were intensive care unit (ICU) stays of $>72 \mathrm{~h}$, ventilator use [200], treatment with antibiotics [201] (notably carbapenems or aminoglycosides [200]), use of antacids [201], and foreign travel, in particular to Asia, Africa, and Northern America [201]. Healthy travelers to countries where CPE are endemic might be at risk, even without contact with the local healthcare system. A CPE was identified in three tourists returning to France from a trip to India (two OXA-181-producing E. coli and one NDM-1-producing E. coli), none of whom had been in contact with health-care institutions while in India [202]. Some other risk factors have been identified such as male gender, age, and previous use of fluoroquinolones, identified during a large Dutch hospital 
outbreak [203]. Prolonged length of stay in hospital represents another risk factor for CRE acquisition [204]. In this case, other colonized patients, health-care workers, and the ICU environment could increase this risk [205].

\section{Epidemiology of OXA-48-like CPE in non-human sources}

Some studies have reported the presence of OXA-48-like producers from non-human sources (Fig. S3).

\section{OXA-48-like producers in the environment}

Several publications have described CPE in the hospital environment [114, 206-208]. However, there is currently little information available with regard to the dissemination of these isolates into the hospital environment. One study has reported the presence of OXA-48-producing E. cloacae and $K$. pneumoniae isolates from environmental surfaces in an Algerian hospital in 2014 [111]. In addition, these authors reported cases of colonization by the same OXA-48-strains in the same period. This finding may indicate that surfaces in hospitals can play a role in the nosocomial acquisition of these isolates. In France, the contamination of patients and the persistence of OXA-48-producing $K$. pneumoniae for many months were observed in an ICU due to presence of the bacteria in mattresses and sinks [128]. A similar case was reported in Belgium where an OXA-48-producing C. freundii was isolated from a contaminated sink in an ICU [83].

Both the antimicrobial agents used for treating infected patients in hospital and multidrug-resistant bacteria may end up in the hospital effluent or in wastewater. The presence of antibiotics in the environment exerts a selective pressure for MDR pathogens. As a result, hospital effluents represent an important pathway for the dissemination of both resistance genes and antibiotic resistant bacteria into the natural environment [209]. Recently, insufficient wastewater management by bulk drug manufacturing facilities in India has led to contamination of water resources with antimicrobial agents, associated with the selection and dissemination of OXA-48 producers [88]. Even after treatment of urban wastewater, a significant number of carbapenemase-producing bacteria can still survive and are then released into aquatic environments such as rivers, lakes, estuaries, or oceans [210]. In this context, OXA-48-producing $S$. marcescens was recovered from water (puddles) in 2011 in Morocco [105]. Galler et al. reported OXA-48-producing $E$. coli and $K$. pneumoniae from Australian wastewater between 2011 and 2012 [211]. Notably, the use of sewage in agriculture can act as a possible route for the dissemination of carbapenemase genes into the natural environment and subsequently into the food chain [211]. Nasri et al. reported OXA-48-producing Enterobacteriaceae from Tunisian wastewater [212]. Recently, in Algeria, OXA-48-likeproducing Enterobacteriaceae (e.g., OXA-48- and OXA244-producing $E$. coli) were isolated from river water. These strains belonged to a diverse ST (ST559, ST38, ST212, ST3541, ST1972, ST2142, and ST3541), with no ST observed in human infections [213]. However, in Algeria, two ST296 E. cloacae strains were isolated during the same period in the environment and in health-care workers [111], and E. coli ST38 and K. pneumoniae ST15 were recovered from wastewater [211], showing that transmission between environment and humans is clearly possible.

\section{OXA-48-like producers in companion animals}

Companion animals can serve as reservoirs of zoonotic bacteria and resistance genes [214]. Evaluation of multiresistance in pets is difficult because there are few surveillance programs compared to data available for livestock, and the data available are generally from retrospective studies of clinical isolates [215].

The emergence of carbapenem-resistant organisms in pets is a worrying trend. This situation may be due to the increasing prescription to pets of antimicrobial substances that are critical to human medicine, but also due to the close contact between pets and their human co-habitants [216]. Although carbapenems are not used in animals in any major jurisdiction, a case of use of these molecules has been reported in dogs for the treatment of urinary tract infection and postoperative infection caused by MDR E. coli when no other class of antibiotic was available [217]. The first report of OXA-48 from companion animals found in $K$. pneumoniae and/or $E$. coli isolates, recovered from six diseased dogs with several comorbidity factors, admitted to a veterinary clinic in Germany in 2012 [64]. Shortly after this episode, in the same region, OXA-48 enzyme was reported in K. pneumoniae and/or E. cloacae from dogs, cats, and a horse in 2009 and 2011 [218]. A study from the US identified $E$. coli strains harboring bla $a_{\mathrm{OXA}}-48$ gene originating in dogs and cats between 2009 and 2013 [60]. In Algeria, five OXA-48-producing $E$. coli were detected in healthy pets (dogs and cats) and a diseased cat (submitted for diagnostic investigation) in one veterinary office and private owners between 2014 and 2015 [72]. Recently, OXA-48-producing $E$. coli were recovered in a large set of healthy cats and dogs in France [219]. Pets harboring bla $a_{\mathrm{OXA}-48}$ gene were associated with diverse STs: ST12, ST131, ST372, ST405, ST648, ST1088, ST1196, ST1431, and ST1800 were found in E. coli isolates, and ST1196 and ST1431 in K. pneumoniae isolates [58, 64, 219]. 
The possible transfer of bacteria from pets is an emerging problem and constitutes a serious threat for public health.

\section{OXA-48-like producers in livestock and production animals}

The current level of intensification of animal production systems leaves production animals vulnerable to disease outbreaks [220]. Thus, various antimicrobial drugs have been administered as veterinary therapeutics in farmed animals [221]. These practices provide favorable conditions for selection, persistence, and spread of MDR bacteria at the farm level [220]. Currently, livestock animals are a source of MDR enterobacteria, and represent risks for public health associated with economic losses in livestock production [222].

The first CPE described from livestock were reported by Fischer et al., from poultry and swine in German farms where VIM-1-producing E. coli and Salmonella enterica were isolated [223, 224]. However, there are only limited and sporadic findings on OXA-48-producing Enterobacteriaceae in livestock. The first report concerned OXA-48-producing $E$. coli strains isolated from fowl species Gallus domesticus in eight livestock farms in 2013 in Lebanon [199]. Another report from Egypt identified $b l a_{\text {OXA-48 }}$ and $b l a_{\text {OXA-181 }}$ in different E. coli isolates recovered from healthy dairy cattle [222]. Recently, the worrying association of $b l a_{\mathrm{OXA}-181}, b l a_{\mathrm{CMY}-2}$, and $\operatorname{arm} A$ with the colistin resistance determinant $m c r-1$ was characterized in an E. coli strain from pigs in Italy [225]. This raises the question of how the potentially contaminated feces are disposed of. As dung is often used as a fertilizer, the $b l a_{\text {OXA-48 }}$ gene might enter the food chain, either directly through consumption of meat, or indirectly from cattle grazing on fertilized pasture. In addition, the use of manure in agriculture can cause the spread of resistance genes in the environment.

Indeed, another study reported coproduction of OXA-48 and/or KPC and/or NDM-producing K. pneumoniae in broiler chickens collected from five different poultry farms in Egypt. In the same study, carbapenemase genes were described in drinking water and in the farmers themselves, suggesting possible transmission between broilers and humans [226]. Thus livestock represents a zoonotic risk for people working in close contact to animals [227], although this relatively limited number of reports about CPEs from livestock may suggest that such bacteria are currently present in livestock at only a very low prevalence. This may reflect the lack of a direct selective pressure, as carbapenems must never be used for livestock animals. A change in this trend might be anticipated as predicted by Poirel et al. who raised a concern of co-selection of these carbapenemase genes under the selective pressure imposed by the use of aminopenicillins or penicillin- $\beta$-lactamase inhibitor combinations in livestock [228].

\section{OXA-48-like producers in the food chain}

The food chain has recently attracted attention because it can serves as reservoir of resistance genes, related to the use of antimicrobial drugs in the livestock sector [229]. Nevertheless, several studies have investigated food products colonized with ESBL/AmpC producers [230]. Few publications have reported CPE detected in food animal products [231-233]. Even better, no studies have reported OXA-48producers in food animal products. However, OXA-181 enzymes were recovered in Klebsiella variicola in fresh vegetables imported from Asia to Switzerland in 2015 [108]. This suggests that vegetables may be contaminated through insufficiently treated water and fertilizers, or may be compromised by the use of biocides during cultivation. This represents a great concern, since these products would not necessarily be cooked to sterilization.

Recently, OXA-48-producing K. pneumoniae was recovered in fresh vegetables from Algeria [234]. Furthermore, this indicates that the food chain could become a reservoir of MDR bacteria and contribute to the spread of these bacteria, but lack of reliable data makes it difficult to assess the attributable risk of different food sources.

\section{OXA-48-like producers in wildlife}

Researchers have suggested that wildlife can play an important role in the dissemination of resistant bacteria [235]. In this respect, the presence of MDR bacteria, including CPE, has recently been reported in wild animals with no apparent prior exposure to antimicrobials. Indeed, NDM-1-producing Salmonella were isolated from wild birds in Germany [236], VIM-1-producing E. coli from yellow-legged gulls in France, and IMP-4 Salmonella from silver gulls in Australia [237]. Wild birds could act as important environmental bio-indicators, as they do for the influenza virus [238]. They could participate in the transmission of resistance mechanism types and the potential intercontinental spread of these antibiotic resistance determinants [239]. Otherwise, no published reports of OXA-48 CPE have so far been isolated, although OXA-48-producing E. coli isolates were detected in our laboratory from wild boars in Algeria [240].

Insects may also act as potential vectors for the spread of MDR bacteria to different environments [241]. One study has described OXA-48-producing E. cloacae belonging to ST296 from cockroaches species Blattella germanica collected in 2015 from the burn unit of Batna University Hospital in Algeria [113]. Within the same period, the same authors identified the emergence of OXA-48-producing $K$. pneumoniae in the same hospital, and hypothesized that these cockroaches can be a source of OXA-48 transmission [113]. The same observation was reported by Davari et al. in houseflies collected in hospitals and slaughterhouses [242]. 


\section{Conclusion}

The emergence and the worldwide spread of CPE is a concern. The reservoirs of these bacteria continue to grow in size and numbers, not only in hospitals, but also in the community, the environment, the food chain, and in animals including pets, livestock, and wild animals. The OXA-48-like enzymes are a good example of how these enzymes evolve continuously. Several publications have reported the appearance of the same resistance genes in animals and humans and the possible transfer of inter-species clonal spread. In addition, these resistant bacteria could have a public health impact if zoonotic transfer occurs. It is clear that the presence of resistance genes in bacteria is associated with the uncontrolled use of antibiotics in human and veterinary medicine. The incidence of resistant bacteria in some sources needs to be closely monitored. Monitoring of antibiotic resistance in animals is mainly concerned with detecting the emergence and preventing possible spread of bacteria that can be pathogenic to humans or animals.

Similarly, the absence of environmental barriers between humans and animals contributes to the spread of antimicrobial resistance in various interconnected ecological niches. Resistance, once developed, is not confined to the limits of the ecological niche where it primarily emerged. If such a scenario occurs, initiatives need to be taken to limit antimicrobial resistance in various environments, for the preservation of human health.

Acknowledgments We thank Sarah Kabani for her help in the preparation and editing of the manuscript.

Funding This work was supported by the National Institute of Health and Medical Research (INSERM).

\section{Compliance with ethical standards}

Conflict of interest The authors declare that they have no conflict of interest.

Ethical approval Not applicable.

Informed consent Not applicable.

\section{References}

1. Grundmann H, Glasner C, Albiger B, Aanensen DM, Tomlinson CT, Andrasević AT et al (2017) Occurrence of carbapenemaseproducing Klebsiella pneumoniae and Escherichia coli in the European survey of carbapenemase-producing Enterobacteriaceae (EuSCAPE): a prospective, multinational study. Lancet Infect Dis 17:153-163

2. Lee W, McDonough MA, Kotra LP, Li Z-H, Silvaggi NR, Takeda $Y$ et al (2001) A 1.2- $\AA$ snapshot of the final step of bacterial cell wall biosynthesis. Proc Natl Acad Sci U S A 98:1427-1431
3. Carlet J (2015) Ten tips on how to win the war against resistance to antibiotics. Intensive Care Med 41:899-901

4. Szmolka A, Nagy B (2013) Multidrug resistant commensal Escherichia coli in animals and its impact for public health. Front Microbiol 4:258

5. Zeng X, Lin J (2013) Beta-lactamase induction and cell wall metabolism in Gram-negative bacteria. Front Microbiol 4:128

6. Cag Y, Caskurlu H, Fan Y, Cao B, Vahaboglu H (2016) Resistance mechanisms. Ann Transl Med 4:326

7. Bush K, Jacoby GA (2010) Updated functional classification of beta-lactamases. Antimicrob Agents Chemother 54:969-976

8. Hawkey PM (2008) The growing burden of antimicrobial resistance. J Antimicrob Chemother 62:i1-i9

9. Kalpoe JS, Al Naiemi N, Poirel L, Nordmann P (2011) Detection of an Ambler class D OXA-48-type $\beta$-lactamase in a Klebsiella pneumoniae strain in The Netherlands. J Med Microbiol 60:677678

10. Shaikh S, Fatima J, Shakil S, Rizvi SMD, Kamal MA (2015) Antibiotic resistance and extended spectrum beta-lactamases: Types, epidemiology and treatment. Saudi J Biol Sci 22:90-101

11. Ewers C, Bethe A, Semmler T, Guenther S, Wieler LH (2012) Extended-spectrum $\beta$-lactamase-producing and AmpCproducing Escherichia coli from livestock and companion animals, and their putative impact on public health: a global perspective. Clin Microbiol Infect 18:646-655

12. Bortolaia V, Hansen KH, Nielsen CA, Fritsche TR, Guardabassi L (2014) High diversity of plasmids harbouring blaCMY-2 among clinical Escherichia coli isolates from humans and companion animals in the upper Midwestern USA. J Antimicrob Chemother 69:1492-1496

13. Shahid M, Sobia F, Singh A, Malik A, Khan HM, Jonas D et al (2009) Beta-lactams and beta-lactamase-inhibitors in current-or potential - clinical practice: a comprehensive update. Crit Rev Microbiol 35:81-108

14. Watanabe M, Iyobe S, Inoue M, Mitsuhashi S (1991) Transferable imipenem resistance in Pseudomonas aeruginosa. Antimicrob Agents Chemother 35:147-151

15. Nordmann P, Mariotte S, Naas T, Labia R, Nicolas MH (1993) Biochemical properties of a carbapenem-hydrolyzing betalactamase from Enterobacter cloacae and cloning of the gene into Escherichia coli. Antimicrob Agents Chemother 37:939-946

16. Naas T, Nordmann P (1994) Analysis of a carbapenemhydrolyzing class A beta-lactamase from Enterobacter cloacae and of its LysR-type regulatory protein. Proc Natl Acad Sci U S A 91:7693-7697

17. Nordmann P, Naas T, Poirel L (2011) Global spread of carbapenemase-producing Enterobacteriaceae. Emerg Infect Dis 17:1791-1798

18. Nordmann P, Dortet L, Poirel L (2012) Carbapenem resistance in Enterobacteriaceae: here is the storm! Trends Mol Med 18:263272

19. Queenan AM, Bush K (2007) Carbapenemases: the versatile betalactamases. Clin Microbiol Rev 20:440-458

20. Poirel L, Héritier C, Tolün V, Nordmann P (2004) Emergence of oxacillinase-mediated resistance to imipenem in Klebsiella pneumoniae. Antimicrob Agents Chemother 48:15-22

21. Carrër A, Poirel L, Yilmaz M, Akan OA, Feriha C, Cuzon G et al (2010) Spread of OXA-48-encoding plasmid in Turkey and beyond. Antimicrob Agents Chemother 54:1369-1373

22. Poirel L, Potron A, Nordmann P (2012) OXA-48-like carbapenemases: the phantom menace. J Antimicrob Chemother 67:1597-1606

23. Evans BA, Amyes SGB (2014) OXA $\beta$-lactamases. Clin Microbiol Rev 27:241-263

24. Kasap M, Torol S, Kolayli F, Dundar D, Vahaboglu H (2013) OXA-162, a novel variant of OXA-48 displays extended 
hydrolytic activity towards imipenem, meropenem and doripenem. J Enzyme Inhib Med Chem 28:990-996

25. Poirel L, Castanheira M, Carrër A, Rodriguez CP, Jones RN, Smayevsky J et al (2011) OXA-163, an OXA-48-related class D $\beta$-lactamase with extended activity toward expanded-spectrum cephalosporins. Antimicrob Agents Chemother 55:2546-2551

26. Potron A, Nordmann P, Lafeuille E, Al Maskari Z, Al Rashdi F, Poirel L (2011) Characterization of OXA-181, a carbapenemhydrolyzing class D beta-lactamase from Klebsiella pneumoniae. Antimicrob Agents Chemother 55:4896-4899

27. Potron A, Nordmann P, Poirel L (2013) Characterization of OXA204, a carbapenem-hydrolyzing class D $\beta$-lactamase from Klebsiella pneumoniae. Antimicrob Agents Chemother 57:633636

28. Potron A, Rondinaud E, Poirel L, Belmonte O, Boyer S, Camiade $S$ et al (2013) Genetic and biochemical characterisation of OXA232, a carbapenem-hydrolysing class $D \beta$-lactamase from Enterobacteriaceae. Int J Antimicrob Agents 41:325-329

29. Oteo J, Hernández JM, Espasa M, Fleites A, Sáez D, Bautista V et al (2013) Emergence of OXA-48-producing Klebsiella pneumoniae and the novel carbapenemases OXA-244 and OXA-245 in Spain. J Antimicrob Chemother 68:317-321

30. Gomez S, Pasteran F, Faccone D, Bettiol M, Veliz O, De Belder D et al (2013) Intrapatient emergence of OXA-247: a novel carbapenemase found in a patient previously infected with OXA-163-producing Klebsiella pneumoniae. Clin Microbiol Infect 19:E233-E235

31. Sampaio JLM, Ribeiro VB, Campos JC, Rozales FP, Magagnin CM, Falci DR et al (2014) Detection of OXA-370, an OXA-48related class D $\beta$-lactamase, in Enterobacter hormaechei from Brazil. Antimicrob Agents Chemother 58:3566-3567

32. Dortet L, Oueslati S, Jeannot K, Tandé D, Naas T, Nordmann P (2015) Genetic and biochemical characterization of OXA-405, an OXA-48-type extended-spectrum $\beta$-lactamase without significant carbapenemase activity. Antimicrob Agents Chemother 59:38233828

33. Potron A, Rondinaud E, Poirel L, Belmonte O, Boyer S, Camiade $S$ et al (2013) Genetic and biochemical characterisation of OXA232, a carbapenem-hydrolysing class D $\beta$-lactamase from Enterobacteriaceae. Int J Antimicrob Agents 41:325-329

34. Poirel L, Héritier C, Nordmann P (2004) Chromosome-encoded ambler class D beta-lactamase of Shewanella oneidensis as a progenitor of carbapenem-hydrolyzing oxacillinase. Antimicrob Agents Chemother 48:348-351

35. Yousfi K, Touati A, Bekal S (2016) Complete genome sequence of an extensively drug-resistant Shewanella xiamenensis strain isolated from Algerian hospital effluents. Genome Announc 4: e01236-e01216

36. Potron A, Poirel L, Nordmann P (2011) Origin of OXA-181, an emerging carbapenem-hydrolyzing oxacillinase, as a chromosomal gene in Shewanella xiamenensis. Antimicrob Agents Chemother 55:4405-4407

37. Zong Z (2012) Discovery of bla(OXA-199), a chromosome-based bla(OXA-48)-like variant, in Shewanella xiamenensis. PLoS One 7:e48280

38. Tacão M, Correia A, Henriques I (2013) Environmental Shewanella xiamenensis strains that carry blaOXA-48 or blaOXA-204 genes: Additional proof for blaOXA-48-like gene origin. Antimicrob Agents Chemother 57:6399-6400

39. Martínez-Martínez L, González-López JJ (2014) Carbapenemases in Enterobacteriaceae: types and molecular epidemiology. Enferm Infecc Microbiol Clin 4:4-9

40. Aubert D, Naas T, Héritier C, Poirel L, Nordmann P (2006) Functional characterization of IS1999, an IS4 family element involved in mobilization and expression of $\beta$-lactam resistance genes. J Bacteriol 188:6506-6514
41. Beyrouthy R, Robin F, Dabboussi F, Mallat H, Hamzé M, Bonnet R (2014) Carbapenemase and virulence factors of Enterobacteriaceae in North Lebanon between 2008 and 2012: evolution via endemic spread of OXA-48. J Antimicrob Chemother 69:2699-2705

42. Giani T, Conte V, Di Pilato V, Aschbacher R, Weber C, Larcher C et al (2012) Escherichia coli from Italy producing OXA-48 carbapenemase encoded by a novel $\operatorname{Tn} 1999$ transposon derivative. Antimicrob Agents Chemother 56:2211-2213

43. Potron A, Nordmann P, Rondinaud E, Jaureguy F, Poirel L (2013) A mosaic transposon encoding OXA-48 and CTX-M-15: towards pan-resistance. J Antimicrob Chemother 68:476-477

44. Skalova A, Chudejova K, Rotova V, Medvecky M, Studentova V, Chudackova E et al (2017) Molecular characterization of OXA48-like-producing Enterobacteriaceae in the Czech Republic and evidence for horizontal transfer of pOXA-48-like plasmids. Antimicrob Agents Chemother 61:e01889-e01816

45. Naas T, Poirel L, Karim A, Nordmann P (1999) Molecular characterization of In50, a class 1 integron encoding the gene for the extended-spectrum beta-lactamase VEB-1 in Pseudomonas aeruginosa. FEMS Microbiol Lett 176:411-419

46. Carattoli A (2013) Plasmids and the spread of resistance. Int J Med Microbiol 303:298-304

47. Carattoli A (2009) Resistance plasmid families in Enterobacteriaceae. Antimicrob Agents Chemother 53:22272238

48. Potron A, Poirel L, Nordmann P (2014) Derepressed transfer properties leading to the efficient spread of the plasmid encoding carbapenemase OXA-48. Antimicrob Agents Chemother 58:467471

49. Turton JF, Doumith M, Hopkins KL, Perry C, Meunier D, Woodford N (2016) Clonal expansion of Escherichia coli ST38 carrying a chromosomally integrated OXA-48 carbapenemase gene. J Med Microbiol 65:538-546

50. Beyrouthy R, Robin F, Delmas J, Gibold L, Dalmasso G, Dabboussi $\mathrm{F}$ et al (2014) IS1R-mediated plasticity of IncL/M plasmids leads to the insertion of blaOXA-48 into the Escherichia coli chromosome. Antimicrob Agents Chemother 58:3785-3790

51. Rojas LJ, Hujer AM, Rudin SD, Wright MS, Domitrovic TN, Marshall SH et al (2017) NDM-5 and OXA-181 beta-lactamases, a significant threat continues to spread in the Americas. Antimicrob Agents Chemother 61:e00454-e00417

52. Dimou V, Dhanji H, Pike R, Livermore DM, Woodford N (2012) Characterization of Enterobacteriaceae producing OXA-48-like carbapenemases in the UK. J Antimicrob Chemother 67:1660 1665

53. Aires CA, Rocha-de-Souza CM, Timm LN, Pereira PS, CarvalhoAssef AP, Asensi MD (2016) Early detection of OXA-370producing Klebsiella pneumoniae ST17 co-harboring blaCTXM-8 in Brazil. Diagn Microbiol Infect Dis 86:434-436

54. Ktari S, Mnif B, Louati F, Rekik S, Mezghani S, Mahjoubi F et al (2011) Spread of Klebsiella pneumoniae isolates producing OXA$48 \beta$-lactamase in a Tunisian university hospital. J Antimicrob Chemother 66:1644-1646

55. Aktaș Z, Kayacan CB, Schneider I, Can B, Midilli K, Bauernfeind A (2008) Carbapenem-hydrolyzing oxacillinase, OXA-48, persists in Klebsiella pneumoniae in Istanbul, Turkey. Chemotherapy 54:101-106

56. Poirel L, Bernabeu S, Fortineau N, Podglajen I, Lawrence C, Nordmann P (2011) Emergence of OXA-48-producing Escherichia coli clone ST38 in France. Antimicrob Agents Chemother 55:4937-4938

57. McGann P, Snesrud E, Ong AC, Appalla L, Koren M, Kwak YI et al (2015) War wound treatment complications due to transfer of an IncN plasmid harboring blaOXA-181 from Morganella 
morganii to CTX-M-27-producing Sequence Type 131 Escherichia coli. Antimicrob Agents Chemother 59:3556-3562

58. Liu X, Thungrat K, Boothe DM (2016) Occurrence of OXA-48 carbapenemase and other $\beta$-lactamase genes in ESBL-producing multidrug resistant Escherichia coli from dogs and cats in the United States, 2009-2013. Front Microbiol 7:1057

59. Hays C, Benouda A, Poirel L, Elouennass M, Nordmann P (2012) Nosocomial occurrence of OXA-48-producing enterobacterial isolates in a Moroccan hospital. Int J Antimicrob Agents 39: $545-547$

60. Al-Marzooq F, Ngeow YF, Tay ST (2015) Emergence of Klebsiella pneumoniae producing dual carbapenemases (NDM1 and OXA-232) and 16S rRNA methylase (armA) isolated from a Malaysian patient returning from India. Int J Antimicrob Agents 45:445-446

61. Barguigua A, El Otmani F, Talmi M, Zerouali K, Timinouni M (2012) Emergence of carbapenem-resistant Enterobacteriaceae isolates in the Moroccan community. Diagn. Microbiol Infect Dis 73:290-291

62. Ben Tanfous F, Alonso CA, Achour W, Ruiz-Ripa L, Torres C, Ben Hassen A (2017) First description of KPC-2-producing Escherichia coli and ST15 OXA-48-positive Klebsiella pneumoniae in Tunisia. Microb Drug Resist 23:365-375

63. Poirel L, Carbonnelle E, Bernabeu S, Gutmann L, Rotimi V, Nordmann P (2012) Importation of OXA-48-producing Klebsiella pneumoniae from Kuwait. J Antimicrob Chemother 67:2051-2052

64. Stolle I, Prenger-Berninghoff E, Stamm I, Scheufen S, Hassdenteufel E, Guenther S et al (2013) Emergence of OXA48 carbapenemase-producing Escherichia coli and Klebsiella pneumoniae in dogs. J Antimicrob Chemother 68:2802-2808

65. Mellouk FZ, Bakour S, Meradji S, Al-Bayssari C, Bentakouk MC, Zouyed F et al (2016) First detection of VIM-4-producing Pseudomonas aeruginosa and OXA-48-producing Klebsiella pneumoniae in Northeastern (Annaba, Skikda) Algeria. Microb Drug Resist 23:335-344

66. Oteo J, Ortega A, Bartolomé R, Bou G, Conejo C, FernándezMartínez M et al (2015) Prospective multicenter study of carbapenemase-producing Enterobacteriaceae from 83 hospitals in Spain reveals high in vitro susceptibility to colistin and meropenem. Antimicrob Agents Chemother 59:3406-3412

67. Bouguenoun W, Bakour S, Bentorki AA, Al Bayssari C, Merad T, Rolain J-M (2016) Molecular epidemiology of environmental and clinical carbapenemase-producing Gram-negative bacilli from hospitals in Guelma, Algeria: Multiple genetic lineages and first report of OXA-48 in Enterobacter cloacae. J Glob Antimicrob Resist 7:135-140

68. Ma L, Wang J-T, Wu T-L, Siu LK, Chuang Y-C, Lin J-C et al (2015) Emergence of OXA-48-producing Klebsiella pneumoniae in Taiwan. PLoS One 10:e0139152

69. Roer L, Hansen F, Thomsen MCF, Knudsen JD, Hansen DS, Wang M et al (2017) WGS-based surveillance of thirdgeneration cephalosporin-resistant Escherichia coli from bloodstream infections in Denmark. J Antimicrob Chemother 72: 1922-1929

70. Villa L, Carattoli A, Nordmann P, Carta C, Poirel L (2013) Complete sequence of the IncT-type plasmid pT-OXA-181 carrying the blaOXA-181 carbapenemase gene from Citrobacter freundii. Antimicrob Agents Chemother 57:1965-1967

71. Lunha K, Chanawong A, Lulitanond A, Wilailuckana C, Charoensri N, Wonglakorn L et al (2016) High-level carbapenem-resistant OXA-48-producing Klebsiella pneumoniae with a novel OmpK36 variant and low-level, carbapenem-resistant, non-porin-deficient, OXA-181-producing Escherichia coli from Thailand. Diagn Microbiol Infect Dis 85:221-226
72. Yousfi M, Touati A, Mairi A, Brasme L, Gharout-Sait A, Guillard $T$ et al (2016) Emergence of carbapenemase-producing Escherichia coli isolated from companion animals in Algeria. Microb Drug Resist 22:342-346

73. Charfi K, Mansour W, Khalifa ABH, Mastouri M, Aouni M, Mammeri H (2015) Emergence of OXA-204 $\beta$-lactamase in Tunisia. Diagn Microbiol Infect Dis 82:314-317

74. Grami R, Mansour W, Ben Haj Khalifa A, Dahmen S, Chatre P, Haenni $M$ et al (2016) Emergence of ST147 Klebsiella pneumoniae producing OXA-204 carbapenemase in a university hospital. Tunisia Microb Drug Resist 22:137-140

75. Koh TH, Cao DYH, Chan KS, Wijaya L, Low SBG, Lam MS et al (2012) bla(OXA-181)-positive Klebsiella pneumoniae, Singapore. Emerg Infect Dis 18:1524-1525

76. Sidjabat HE, Townell N, Nimmo GR, George NM, Robson J, Vohra R et al (2015) Dominance of IMP-4-producing Enterobacter cloacae among carbapenemase-producing Enterobacteriaceae in Australia. Antimicrob Agents Chemother 59:4059-4066

77. Hammerum AM, Littauer P, Hansen F (2015) Detection of Klebsiella pneumoniae co-producing NDM-7 and OXA-181, Escherichia coli producing NDM-5 and Acinetobacter baumannii producing OXA-23 in a single patient. Int J Antimicrob Agents 46:597-598

78. Hall JM, Corea E, Sanjeewani HDA, Inglis TJJ (2014) Molecular mechanisms of $\beta$-lactam resistance in carbapenemase-producing Klebsiella pneumoniae from Sri Lanka. J Med Microbiol 63: 1087-1092

79. Ouertani R, Limelette A, Guillard T, Brasme L, Jridi Y, Barguellil F et al (2016) First report of nosocomial infection caused by Klebsiella pneumoniae ST147 producing OXA-48 and VEB-8 $\beta$-lactamases in Tunisia. J Glob Antimicrob Resist 4:53-56

80. Balm MND, Ngan G, Jureen R, Lin RTP, Teo JWP (2013) OXA181-producing Klebsiella pneumoniae establishing in Singapore. BMC Infect Dis 13:58

81. Ben Nasr A, Decré D, Compain F, Genel N, Barguellil F, Arlet G (2013) Emergence of NDM-1 in association with OXA-48 in Klebsiella pneumoniae from Tunisia. Antimicrob Agents Chemother 57:4089-4090

82. Cizmeci Z, Aktas E, Otlu B, Acikgoz O, Ordekci S (2017) Molecular characterization of carbapenem-resistant Enterobacteriaceae yields increasing rates of NDM-1 carbapenemases and colistin resistance in an OXA-48- endemic area. J Chemother 9:1-7

83. De Geyter D, Blommaert L, Verbraeken N, Sevenois M, Huyghens L, Martini H et al (2017) The sink as a potential source of transmission of carbapenemase-producing Enterobacteriaceae in the intensive care unit. Antimicrob Resist Infect Control 6:24

84. Dortet L, Cuzon G, Ponties V, Nordmann P (2017) Trends in carbapenemase-producing Enterobacteriaceae, France, 2012 to 2014. Euro Surveill 9:22

85. Huang TD, Bogaerts P, Berhin C, Hoebeke M, Bauraing C, Glupczynski $Y$ et al (2017) Increasing proportion of carbapenemase-producing Enterobacteriaceae and emergence of a MCR-1 producer through a multicentric study among hospitalbased and private laboratories in Belgium from September to November 2015. Euro Surveill 11:22

86. Khajuria A, Praharaj AK, Kumar M, Grover N (2014) Emergence of Escherichia coli, co-producing NDM-1 and OXA-48 carbapenemases, in urinary isolates, at a tertiary care centre at Central India. J Clin Diagn Res 8:DC01-DC04

87. Khalifa HO, Soliman AM, Ahmed AM, Shimamoto T, Hara T, Ikeda $\mathrm{M}$ et al (2017) High carbapenem resistance in clinical Gramnegative pathogens isolated in Egypt. Microb Drug Resist. https:// doi.org/10.1089/mdr.2015.0339 
88. Lübbert C, Baars C, Dayakar A, Lippmann N, Rodloff AC, Kinzig $M$ et al (2017) Environmental pollution with antimicrobial agents from bulk drug manufacturing industries in Hyderabad, South India, is associated with dissemination of extended-spectrum beta-lactamase and carbapenemase-producing pathogens. Infection 45:479-491

89. Memish ZA, Assiri A, Almasri M, Roshdy H, Hathout H, Kaase $M$ et al (2015) Molecular characterization of carbapenemase production among Gram-negative bacteria in Saudi Arabia. Microb Drug Resist 21:307-314

90. Peirano G, Ahmed-Bentley J, Fuller J, Rubin JE, Pitout JDD (2014) Travel-related carbapenemase-producing Gram-negative bacteria in Alberta, Canada: the first 3 years. J Clin Microbiol $52: 1575-1581$

91. Samuelsen Ø, Naseer U, Karah N, Lindemann PC, Kanestrøm A, Leegaard TM et al (2013) Identification of Enterobacteriaceae isolates with OXA-48 and coproduction of OXA-181 and NDM1 in Norway. J Antimicrob Chemother 68:1682-1685

92. Solgi H, Badmasti F, Aminzadeh Z, Giske CG, Pourahmad M, Vaziri F et al (2017) Molecular characterization of intestinal carriage of carbapenem-resistant Enterobacteriaceae among inpatients at two Iranian university hospitals: first report of coproduction of blaNDM-7 and blaOXA-48. Eur J Clin Microbiol Infect Dis. https://doi.org/10.1007/s10096-017-3035-3

93. Cho SY, Huh HJ, Baek JY, Chung NY, Ryu JG, Ki C-S et al (2015) Klebsiella pneumoniae co-producing NDM-5 and OXA-181 carbapenemases, South Korea. Emerg Infect Dis 21:1088-1089

94. Lázaro-Perona F, Sarria-Visa A, Ruiz-Carrascoso G, Mingorance J, García-Rodríguez J, Gómez-Gil R (2017) Klebsiella pneumoniae co-producing NDM-7 and OXA-48 carbapenemases isolated from a patient with prolonged hospitalisation. Int $\mathrm{J}$ Antimicrob Agents 49:112-113

95. Low Y-M, Yap PS-X, Abdul Jabar K, Ponnampalavanar S, Karunakaran R, Velayuthan R et al (2017) The emergence of carbapenem resistant Klebsiella pneumoniae in Malaysia: correlation between microbiological trends with host characteristics and clinical factors. Antimicrob Resist Infect Control 6:5

96. Poirel L, Abdelaziz MO, Bernabeu S, Nordmann P (2013) Occurrence of OXA-48 and VIM-1 carbapenemase-producing Enterobacteriaceae in Egypt. Int J Antimicrob Agents 41:90-91

97. Pfeifer Y, Schlatterer K, Engelmann E, Schiller RA, Frangenberg HR, Stiewe D et al (2012) Emergence of OXA-48-type carbapenemase-producing Enterobacteriaceae in German Hospitals. Antimicrob Agents Chemother 56:2125-2128

98. Lascols C, Peirano G, Hackel M, Laupland KB, Pitout JDD (2013) Surveillance and molecular epidemiology of Klebsiella pneumoniae isolates that produce carbapenemases: first report of OXA-48-like enzymes in North America. Antimicrob Agents Chemother 57:130-136

99. Al-Agamy MH, Aljallal A, Radwan HH, Shibl AM (2017) Characterization of carbapenemases, ESBLs, and plasmidmediated quinolone determinants in carbapenem-insensitive Escherichia coli and Klebsiella pneumoniae in Riyadh hospitals. J Infect Public Health. https://doi.org/10.1016/j.jiph.2017.03.010

100. Moquet O, Bouchiat C, Kinana A, Seck A, Arouna O, Bercion R et al (2011) Class D OXA-48 carbapenemase in multidrugresistant enterobacteria, Senegal. Emerg Infect Dis 17:143-144

101. Mnif B, Ktari S, Chaari A, Medhioub F, Rhimi F, Bouaziz M et al (2013) Nosocomial dissemination of Providencia stuartii isolates carrying blaOXA-48, blaPER-1, blaCMY-4 and qnrA6 in a Tunisian hospital. J Antimicrob Chemother 68:329-332

102. Nazic H, Poirel L, Nordmann P (2005) Further identification of plasmid-mediated quinolone resistance determinant in Enterobacteriaceae in Turkey. Antimicrob Agents Chemother 49:2146-2147
103. Peirano G, Bradford PA, Kazmierczak KM, Badal RE, Hackel M, Hoban DJ et al (2014) Global incidence of carbapenemaseproducing Escherichia coli ST131. Emerg Infect Dis 20:19281931

104. Galani I, Anagnostoulis G, Chatzikonstantinou M, Petrikkos G, Souli M (2016) Emergence of Klebsiella pneumoniae coproducing OXA-48, CTX-M-15, and ArmA in Greece. Clin Microbiol Infect 22:898-899

105. Potron A, Poirel L, Bussy F, Nordmann P (2011) Occurrence of the carbapenem-hydrolyzing beta-lactamase gene blaOXA-48 in the environment in Morocco. Antimicrob Agents Chemother 55: $5413-5414$

106. Ruiz-Garbajosa P, Hernández-García M, Beatobe L, Tato M, Méndez MI, Grandal M et al (2016) A single-day point-prevalence study of faecal carriers in long-term care hospitals in Madrid (Spain) depicts a complex clonal and polyclonal dissemination of carbapenemase-producing Enterobacteriaceae. J Antimicrob Chemother 71:348-352

107. Sampaio JL, Ribeiro VB, Campos JC, Rozales FP, Magagnin CM, Falci DR et al (2014) Detection of OXA-370, an OXA-48-Related Class D $\beta$-Lactamase, in Enterobacter hormaechei from Brazil. Antimicrob Agents Chemother 58:3566-3567

108. Zurfluh K, Poirel L, Nordmann P, Klumpp J, Stephan R (2015) First detection of Klebsiella variicola producing OXA-181 carbapenemase in fresh vegetable imported from Asia to Switzerland. Antimicrob Resist Infect Control 4:38

109. Djahmi N, Dunyach-Remy C, Pantel A, Dekhil M, Sotto A, Lavigne J-P (2014) Epidemiology of carbapenemase-producing Enterobacteriaceae and Acinetobacter baumannii in Mediterranean Countries. Biomed Res 2014:305784

110. Agabou A, Pantel A, Ouchenane Z, Lezzar N, Khemissi S, Satta D et al (2014) First description of OXA-48-producing Escherichia coli and the pandemic clone ST131 from patients hospitalised at a military hospital in Algeria. Eur J Clin Microbiol Infect Dis 33: 1641-1646

111. Bouguenoun W, Bakour S, Bentorki AA, Al Bayssari C, Merad T, Rolain J-M (2016) Molecular epidemiology of environmental and clinical carbapenemase-producing Gram-negative bacilli from hospitals in Guelma, Algeria: multiple genetic lineages and first report of OXA-48 in Enterobacter cloacae. J Glob Antimicrob Resist 7:135-140

112. Cuzon G, Bentchouala C, Vogel A, Héry M, Lezzar A, Smati F et al (2015) First outbreak of OXA-48-positive carbapenemresistant Klebsiella pneumoniae isolates in Constantine, Algeria. Int J Antimicrob Agents 46:725-727

113. Loucif L, Kassah-Laouar A, Saidi M, Messala A, Chelaghma W, Rolain J-M (2016) Outbreak of OXA-48-producing Klebsiella pneumoniae involving a sequence type 101 clone in Batna University Hospital, Algeria. Antimicrob Agents Chemother 60: 7494-7497

114. Yagoubat M, Ould El-Hadj-Khelil A, Malki A, Bakour S, Touati A, Rolain J-M (2016) Genetic characterisation of carbapenemresistant Gram-negative bacteria isolated from the University Hospital Mohamed Boudiaf in Ouargla, southern Algeria. J Glob Antimicrob Resist 8:55-59

115. Cuzon G, Naas T, Bogaerts P, Glupczynski Y, Huang T-D, Nordmann P (2008) Plasmid-encoded carbapenem-hydrolyzing beta-lactamase OXA-48 in an imipenem-susceptible Klebsiella pneumoniae strain from Belgium. Antimicrob Agents Chemother 52:3463-3464

116. Yusuf E, Huang T-D, Schallier A, Trémérie J-M, Mertens R, Jans B et al (2016) OXA-48 producing Klebsiella pneumoniae in a household contact of a previously infected patient: person-toperson transmission or coincidental community acquisition? Microb Drug Resist 22:134-136 
117. De Laveleye M, Huang TD, Bogaerts P, Berhin C, Bauraing C, Sacré $P$ et al (2016) Increasing incidence of carbapenemaseproducing Escherichia coli and Klebsiella pneumoniae in Belgian hospitals. Eur J Clin Microbiol Infect Dis 36:139-146

118. Sabtcheva S, Ivanov IN, Todorova B, Simeonov Y, Dobreva E, Ivanova K et al (2016) Detection and characterization of OXA-48producing Klebsiella pneumoniae originated in Bulgaria. J Chemother 28:450-453

119. Guo L, An J, Ma Y, Ye L, Luo Y, Tao C et al (2016) Nosocomial outbreak of OXA-48-producing Klebsiella pneumoniae in a Chinese hospital: clonal transmission of ST147 and ST383. PLoS One 11:e0160754

120. Vanegas JM, Ospina WP, Felipe Higuita-Gutiérrez L, Natalia Jiménez J (2016) First reported case of an OXA-48-producing isolate from a Colombian patient. J Glob Antimicrob Resist 6: 67-68

121. Bedenić B, Sardelić S, Luxner J, Bošnjak Z, Varda-Brkić D, Lukić-Grlić A et al (2016) Molecular characterization of class B carbapenemases in advanced stage of dissemination and emergence of class D carbapenemases in Enterobacteriaceae from Croatia. Infect Genet Evol 43:74-82

122. Gedebjerg A, Hasman H, Sørensen CM, Wang M (2015) An OXA-48-producing Escherichia coli isolated from a Danish patient with no hospitalization abroad. Infect Dis 47:593-595

123. Hammerum AM, Larsen AR, Hansen F, Justesen US, Friis-Møller A, Lemming LE et al (2012) Patients transferred from Libya to Denmark carried OXA-48-producing Klebsiella pneumoniae, NDM-1-producing Acinetobacter baumannii and meticillinresistant Staphylococcus aureus. Int J Antimicrob Agents 40: 191-192

124. Decre D, Birgand G, Geneste D, Maury E, Petit JC, Barbut F et al (2010) Possible importation and subsequent cross-transmission of OXA-48-producing Klebsiella pneumoniae, France, 2010. Euro Surveill 18:15

125. Levast M, Poirel L, Carrër A, Deiber M, Decroisette E, Mallaval F-O et al (2011) Transfer of OXA-48-positive carbapenemresistant Klebsiella pneumoniae from Turkey to France. J Antimicrob Chemother 66:944-945

126. Pantel A, Boutet-Dubois A, Jean-Pierre H, Marchandin H, Sotto A, Lavigne J-P et al (2014) French regional surveillance program of carbapenemase-producing Gram-negative bacilli: results from a 2-year period. Eur J Clin Microbiol Infect Dis 33:2285-2292

127. Pantel A, Marchandin H, Prère M-F, Boutet-Dubois A, BrieuRoche N, Gaschet A et al (2015) Faecal carriage of carbapenemase-producing Gram-negative bacilli in hospital settings in southern France. Eur J Clin Microbiol Infect Dis 34: 899-904

128. Pantel A, Richaud-Morel B, Cazaban M, Bouziges N, Sotto A, Lavigne J-P (2016) Environmental persistence of OXA-48producing Klebsiella pneumoniae in a French intensive care unit. Am J Infect Control 44:366-368

129. Robert J, Pantel A, Mérens A, Lavigne J-P, Nicolas-Chanoine MH, ONERBA's Carbapenem Resistance Study Group (2014) Incidence rates of carbapenemase-producing Enterobacteriaceae clinical isolates in France: a prospective nationwide study in 2011-12. J Antimicrob Chemother 69:2706-2712

130. Kaase M, Schimanski S, Schiller R, Beyreiß B, Thürmer A, Steinmann J et al (2016) Multicentre investigation of carbapenemase-producing Escherichia coli and Klebsiella pneumoniae in German hospitals. Int J Med Microbiol 306:415420

131. Kola A, Piening B, Pape U-F, Veltzke-Schlieker W, Kaase M, Geffers C et al (2015) An outbreak of carbapenem-resistant OXA-48-producing Klebsiella pneumoniae associated to duodenoscopy. Antimicrob Resist Infect Control 4:8
132. Voulgari E, Zarkotou O, Ranellou K, Karageorgopoulos DE, Vrioni G, Mamali V et al (2013) Outbreak of OXA-48 carbapenemase-producing Klebsiella pneumoniae in Greece involving an ST11 clone. J Antimicrob Chemother 68:84-88

133. Kovács K, Nyul A, Mestyán G, Melegh S, Fenyvesi H, Jakab G et al (2016) Emergence and interhospital spread of OXA-48producing Klebsiella pneumoniae ST395 clone in Western Hungary. Infect Dis 28:1-3

134. Borah VV, Saikia KK, Hazarika NK (2016) First report on the detection of OXA-48 $\beta$-lactamase gene in Escherichia coli and Pseudomonas aeruginosa co-infection isolated from a patient in a tertiary care hospital in Assam. Indian J Med Microbiol 34:252253

135. Damavandi M-S, Gholipour A, Latif Pour M (2016) Prevalence of class D carbapenemases among extended-spectrum $\beta$-lactamases producing Escherichia coli isolates from educational hospitals in Shahrekord. J Clin Diagn Res 10:DC01-DC05

136. Hojabri Z, Mirmohammadkhani M, Kamali F, Ghassemi K, Taghavipour S, Pajand O (2017) Molecular epidemiology of Escherichia coli sequence type 131 and its $\mathrm{H} 30 / \mathrm{H} 30-\mathrm{Rx}$ subclones recovered from extra-intestinal infections: first report of OXA-48 producing ST131 clone from Iran. Eur J Clin Microbiol Infect Dis. https://doi.org/10.1007/s10096-017-3021-9

137. Shahcheraghi F, Aslani MM, Mahmoudi H, Karimitabar Z, Solgi $\mathrm{H}$, Bahador A et al (2017) Molecular study of carbapenemase genes in clinical isolates of Enterobacteriaceae resistant to carbapenems and determining their clonal relationship using pulsedfield gel electrophoresis. J Med Microbiol 66:570-576

138. Morris D, O'Connor M, Izdebski R, Corcoran M, Ludden CE, McGrath E et al (2016) Dissemination of clonally related multidrug-resistant Klebsiella pneumoniae in Ireland. Epidemiol Infect 144:443-448

139. O'Brien DJ, Wrenn C, Roche C, Rose L, Fenelon C, Flynn A et al (2011) First isolation and outbreak of OXA-48-producing Klebsiella pneumoniae in an Irish hospital. Euro Surveill 21:16

140. Goren MG, Chmelnitsky I, Carmeli Y, Navon-Venezia S (2011) Plasmid-encoded OXA-48 carbapenemase in Escherichia coli from Israel. J Antimicrob Chemother 66:672-673

141. Lerner A, Solter E, Rachi E, Adler A, Rechnitzer H, Miron D et al (2016) Detection and characterization of carbapenemaseproducing Enterobacteriaceae in wounded Syrian patients admitted to hospitals in northern Israel. Eur J Clin Microbiol Infect Dis 35:149-154

142. Kocsis E, Savio C, Piccoli M, Cornaglia G, Mazzariol A (2013) Klebsiella pneumoniae harbouring OXA-48 carbapenemase in a Libyan refugee in Italy. Clin Microbiol Infect 19:E409-E411

143. Yu F, Wang S, Lv J, Qi X, Guo Y, Tang Y-W et al (2017) Coexistence of OXA-48-producing Klebsiella pneumoniae and Escherichia coli in a hospitalized patient who returned from Europe to China. Antimicrob Agents Chemother 61:e02580 e02516

144. Aqel AA, Giakkoupi P, Alzoubi H, Masalha I, Ellington MJ, Vatopoulos A (2017) Detection of OXA-48-like and NDM carbapenemases producing Klebsiella pneumoniae in Jordan: a pilot study. J Infect Public Health 10:150-155

145. Baroud M, Dandache I, Araj GF, Wakim R, Kanj S, Kanafani Z et al (2013) Underlying mechanisms of carbapenem resistance in extended-spectrum $\beta$-lactamase-producing Klebsiella pneumoniae and Escherichia coli isolates at a tertiary care centre in Lebanon: role of OXA-48 and NDM-1 carbapenemases. Int J Antimicrob Agents 41:75-79

146. Christophy R, Osman M, Mallat H, Achkar M, Ziedeh A, Moukaddem W et al (2017) Prevalence, antibiotic susceptibility and characterization of antibiotic resistant genes among carbapenem-resistant Gram-negative bacilli and yeast in intestinal 
flora of cancer patients in North Lebanon. J Infect Public Health. https://doi.org/10.1016/j.jiph.2016.10.009

147. Dandachi I, Salem Sokhn E, Najem E, Azar E, Daoud Z (2016) Carriage of beta-lactamase-producing Enterobacteriaceae among nursing home residents in north Lebanon. Int J Infect Dis 45:24 31

148. Hammoudi D, Ayoub Moubareck C, Aires J, Adaime A, Barakat A, Fayad N et al (2014) Countrywide spread of OXA-48 carbapenemase in Lebanon: surveillance and genetic characterization of carbapenem-non-susceptible Enterobacteriaceae in 10 hospitals over a one-year period. Int J Infect Dis 29:139-144

149. Matar GM, Cuzon G, Araj GF, Naas T, Corkill J, Kattar MM et al (2008) Oxacillinase-mediated resistance to carbapenems in Klebsiella pneumoniae from Lebanon. Clin Microbiol Infect 14: 887-888

150. Mathlouthi N, Al-Bayssari C, El Salabi A, Bakour S, Ben Gwierif S, Zorgani AA et al (2016) Carbapenemases and extendedspectrum $\beta$-lactamases producing Enterobacteriaceae isolated from Tunisian and Libyan hospitals. J Infect Dev Ctries 10:718 727

151. Pirš M, Andlovic A, Cerar T, Žohar-Čretnik T, Kobola L, Kolman $\mathrm{J}$ et al (2011) A case of OXA-48 carbapenemase-producing Klebsiella pneumoniae in a patient transferred to Slovenia from Libya, November 2011. Euro Surveill 16:20042

152. Benouda A, Touzani O, Khairallah M-T, Araj GF, Matar GM (2010) First detection of oxacillinase-mediated resistance to carbapenems in Klebsiella pneumoniae from Morocco. Ann Trop Med Parasitol 104:327-330

153. Girlich D, Bouihat N, Poirel L, Benouda A, Nordmann P (2014) High rate of faecal carriage of extended-spectrum $\beta$-lactamase and OXA-48 carbapenemase-producing Enterobacteriaceae at a university hospital in Morocco. Clin Microbiol Infect 20:350-354

154. Dautzenberg MJ, Ossewaarde JM, de Kraker ME, van der Zee A, van Burgh S, de Greeff SC et al (2014) Successful control of a hospital-wide outbreak of OXA-48 producing Enterobacteriaceae in the Netherlands, 2009 to 2011. Euro Surveill 6:19

155. Vlek AL, Frentz D, Haenen A, Bootsma HJ, Notermans DW, Frakking FN et al (2016) Detection and epidemiology of carbapenemase producing Enterobacteriaceae in the Netherlands in 2013-2014. Eur J Clin Microbiol Infect Dis 35:1089-1096

156. Willemsen I, van Esser J, Kluytmans-van den Bergh M, Zhou K, Rossen JW, Verhulst C et al (2016) Retrospective identification of a previously undetected clinical case of OXA-48-producing $K$. pneumoniae and E. coli: the importance of adequate detection guidelines. Infection 44:107-110

157. Potron A, Kalpoe J, Poirel L, Nordmann P (2011) European dissemination of a single OXA-48-producing Klebsiella pneumoniae clone. Clin Microbiol Infect 17:E24-E26

158. Czobor I, Novais Â, Rodrigues C, Chifiriuc MC, Mihăescu G, Lazăr V et al (2016) Efficient transmission of IncFIIY and IncL plasmids and Klebsiella pneumoniae ST101 clone producing OXA-48, NDM-1 or OXA-181 in Bucharest hospitals. Int J Antimicrob Agents 48:223-224

159. Ageevets VA, Partina IV, Lisitsyna ES, Ilina EN, Lobzin YV, Shlyapnikov SA et al (2014) Emergence of carbapenemaseproducing Gram-negative bacteria in Saint Petersburg, Russia. Int J Antimicrob Agents 44:152-155

160. Alotaibi FE, Bukhari EE, Al-Mohizea MM, Hafiz T, Essa EB, AlTokhais YI (2017) Emergence of carbapenem-resistant Enterobacteriaceae isolated from patients in a university hospital in Saudi Arabia. Epidemiology, clinical profiles and outcomes. J Infect Public Health 10:667-673

161. Koh TH, Ko K, Jureen R, Deepak RN, Tee NWS, Tan TY et al (2015) High counts of carbapenemase-producing Enterobacteriaceae in hospital sewage. Infect Control Hosp Epidemiol 36:619-621
162. Singh-Moodley A, Perovic O (2016) Antimicrobial susceptibility testing in predicting the presence of carbapenemase genes in Enterobacteriaceae in South Africa. BMC Infect Dis 16:536

163. Brañas P, Gil M, Villa J, Orellana MÁ, Chaves F (2016) Molecular epidemiology of carbapenemase-producing Enterobacteriaceae infection/colonisation in a hospital in Madrid. Enferm Infecc Microbiol Clin. https://doi.org/10.1016/j.eimc.2016.10.004

164. Cubero M, Cuervo G, Dominguez MÁ, Tubau F, Martí S, Sevillano E et al (2015) Carbapenem-resistant and carbapenemsusceptible isogenic isolates of Klebsiella pneumoniae ST101 causing infection in a tertiary hospital. BMC Microbiol 15:177

165. Fernández J, Montero I, Fleites A, Rodicio MR (2014) Cluster of Escherichia coli isolates producing a plasmid-mediated OXA-48 $\beta$-lactamase in a Spanish hospital in 2012. J Clin Microbiol 52: 3414-3417

166. Fernández J, Poirel L, Rodicio MR, Nordmann P (2016) Concomitant and multiclonal dissemination of OXA-48producing Klebsiella pneumoniae in a Spanish hospital. J Antimicrob Chemother 71:1734-1736

167. Madueño A, González García J, Fernández-Romero S, Oteo J, Lecuona M (2017) Dissemination and clinical implications of multidrug-resistant Klebsiella pneumoniae isolates producing OXA-48 in a Spanish hospital. J Hosp Infect 96:116-122

168. Oteo J, Saez D, Bautista V, Fernández-Romero S, HernándezMolina JM, Pérez-Vázquez M et al (2013) Carbapenemaseproducing Enterobacteriaceae in Spain in 2012. Antimicrob Agents Chemother 57:6344-6347

169. Rios E, López MC, Rodríguez-Avial I, Culebras E, Picazo JJ (2016) Detection of Escherichia coli ST131 complex (ST705) and Klebsiella pneumoniae ST15 among fecal carriage of extended-spectrum betalactamase- and carbapenemaseproducing Enterobacteriaceae. J Med Microbiol 66:169-174

170. Dortet L, Poirel L, Al Yaqoubi F, Nordmann P (2012) NDM-1, OXA-48 and OXA-181 carbapenemase-producing Enterobacteriaceae in Sultanate of Oman. Clin Microbiol Infect 18:E144-E148

171. Löfmark S, Sjöström K, Mäkitalo B, Edquist P, Tegmark Wisell K, Giske CG (2015) Carbapenemase-producing Enterobacteriaceae in Sweden 2007-2013: Experiences from seven years of systematic surveillance and mandatory reporting. Drug Resist Updat 20: 29-38

172. Seiffert SN, Perreten V, Johannes S, Droz S, Bodmer T, Endimiani A (2014) OXA-48 carbapenemase-producing Salmonella enterica serovar Kentucky isolate of sequence type 198 in a patient transferred from Libya to Switzerland. Antimicrob Agents Chemother 58:2446-2449

173. Zurfluh K, Nüesch-Inderbinen MT, Poirel L, Nordmann P, Hächler H, Stephan R (2015) Emergence of Escherichia coli producing OXA-48 $\beta$-lactamase in the community in Switzerland. Antimicrob Resist Infect Control 4:9

174. Cuzon G, Naas T, Lesenne A, Benhamou M, Nordmann P (2010) Plasmid-mediated carbapenem-hydrolysing OXA-48 betalactamase in Klebsiella pneumoniae from Tunisia. Int $\mathrm{J}$ Antimicrob Agents 36:91-93

175. Hammami S, Dahdeh C, Mamlouk K, Ferjeni S, Maamar E, Hamzaoui Z et al (2017) Rectal carriage of extended-spectrum beta-lactamase and carbapenemase producing Gram-negative bacilli in intensive care units in Tunisia. Microb Drug Resist 23:695702

176. Lafeuille E, Decré D, Mahjoub-Messai F, Bidet P, Arlet G, Bingen E (2013) OXA-48 carbapenemase-producing Klebsiella pneumoniae isolated from Libyan patients. Microb Drug Resist 19:491-497

177. Lahlaoui H, Poirel L, Barguellil F, Moussa MB, Nordmann P (2012) Carbapenem-hydrolyzing class D $\beta$-lactamase OXA-48 
in Klebsiella pneumoniae isolates from Tunisia. Eur J Clin Microbiol Infect Dis 31:937-939

178. Lahlaoui H, Bonnin RA, Moussa MB, Khelifa ABH, Naas T (2017) First report of OXA-232-producing Klebsiella pneumoniae strains in Tunisia. Diagn Microbiol Infect Dis 88:195-197

179. Çakar A, Akyön Y, Gür D, Karatuna O, Öğünç D, Özhak Baysan $B$ et al (2016) Investigation of carbapenemases in carbapenemresistant Escherichia coli and Klebsiella pneumoniae strains isolated in 2014 in Turkey. Mikrobiyol 50:21-33

180. Carrër A, Poirel L, Eraksoy H, Cagatay AA, Badur S, Nordmann P (2008) Spread of OXA-48-positive carbapenem-resistant Klebsiella pneumoniae isolates in Istanbul, Turkey. Antimicrob Agents Chemother 52:2950-2954

181. Demiray T, Koroglu M, Ozbek A, Altindis M (2016) A rare cause of infection, Raoultella planticola: emerging threat and new reservoir for carbapenem resistance. Infection 44:713-717

182. Gülmez D, Woodford N, Palepou M-FI, Mushtaq S, Metan G, Yakupogullari Y et al (2008) Carbapenem-resistant Escherichia coli and Klebsiella pneumoniae isolates from Turkey with OXA48-like carbapenemases and outer membrane protein loss. Int J Antimicrob Agents 31:523-526

183. Kilic A, Aktas Z, Bedir O, Gumral R, Bulut Y, Stratton C et al (2011) Identification and characterization of OXA-48 producing, carbapenem-resistant Enterobacteriaceae isolates in Turkey. Ann Clin Lab Sci 41:161-166

184. Magagnin CM, Rozales FP, Antochevis L, Nunes LS, Martins AS, Barth AL et al (2017) Dissemination of blaOXA-370 gene among several Enterobacteriaceae species in Brazil. Eur J Clin Microbiol Infect Dis. https://doi.org/10.1007/s10096-017-3012-x

185. Majewski P, Wieczorek P, Sacha PT, Frank M, Juszczyk G, Ojdana D et al (2014) Emergence of OXA-48 carbapenemaseproducing Enterobacter cloacae ST89 infection in Poland. Int J Infect Dis 25:107-109

186. Day MR, Meunier D, Doumith M, de Pinna E, Woodford N, Hopkins KL (2015) Carbapenemase-producing Salmonella enterica isolates in the UK. J Antimicrob Chemother 70:21652167

187. Hasassri ME, Boyce TG, Norgan AP, Cunningham SA, Jeraldo PR, Weissman SJ et al (2016) An immunocompromised child with bloodstream infection caused by two Escherichia coli strains, one harboring NDM-5 and the other harboring OXA-48-like carbapenemase. Antimicrob Agents Chemother 60:3270-3275

188. Potron A, Poirel L, Rondinaud E, Nordmann P (2013) Intercontinental spread of OXA-48 beta-lactamase-producing Enterobacteriaceae over a 11-year period, 2001 to 2011. Euro Surveill 1:18

189. Pitart C, Solé M, Roca I, Fàbrega A, Vila J, Marco F (2011) First outbreak of a plasmid-mediated carbapenem-hydrolyzing OXA48 beta-lactamase in Klebsiella pneumoniae in Spain. Antimicrob Agents Chemother 55:4398-4401

190. Adler A, Shklyar M, Schwaber MJ, Navon-Venezia S, Dhaher Y, Edgar R et al (2011) Introduction of OXA-48-producing Enterobacteriaceae to Israeli hospitals by medical tourism. J Antimicrob Chemother 66:2763-2766

191. Skálová A, Chudějová K, Rotová V, Medvecky M, Študentová V, Chudáčková E et al (2017) Molecular characterization of OXA48-like-producing Enterobacteriaceae in the Czech Republic: evidence for horizontal transfer of pOXA-48-like plasmids. Antimicrob. Agents Chemother 61:e01889-e01816

192. Liapis E, Pantel A, Robert J, Nicolas-Chanoine M-H, Cavalié L, van der Mee-Marquet N et al (2014) Molecular epidemiology of OXA-48-producing Klebsiella pneumoniae in France. Clin Microbiol Infect 20:O1121-O1123

193. Findlay J, Hopkins KL, Loy R, Doumith M, Meunier D, Hill R et al (2017) OXA-48-like carbapenemases in the UK: an analysis of isolates and cases from 2007 to 2014. J Antimicrob Chemother 72:1340-1349

194. Österblad M, Kirveskari J, Hakanen AJ, Tissari P, Vaara M, Jalava J (2012) Carbapenemase-producing Enterobacteriaceae in Finland: the first years (2008-11). J Antimicrob Chemother 67: 2860-2864

195. Damjanova I, Tóth A, Pászti J, Hajbel-Vékony G, Jakab M, Berta $\mathrm{J}$ et al (2008) Expansion and countrywide dissemination of ST11, ST15 and ST147 ciprofloxacin-resistant CTX-M-15-type betalactamase-producing Klebsiella pneumoniae epidemic clones in Hungary in 2005-the new "MRSAs"? J Antimicrob Chemother 62:978-985

196. Göttig S, Gruber TM, Stecher B, Wichelhaus TA, Kempf VAJ (2015) In vivo horizontal gene transfer of the carbapenemase OXA-48 during a nosocomial outbreak. Clin Infect Dis 60: $1808-1815$

197. Ortega A, Sáez D, Bautista V, Fernández-Romero S, Lara N, Aracil B et al (2016) Carbapenemase-producing Escherichia coli is becoming more prevalent in Spain mainly because of the polyclonal dissemination of OXA-48. J Antimicrob Chemother 71: 2131-2138

198. Nicolas-Chanoine M-H, Bertrand X, Madec J-Y (2014) Escherichia coli ST131, an intriguing clonal group. Clin Microbiol Rev 27:543-574

199. Al Bayssari C, Olaitan AO, Dabboussi F, Hamze M, Rolain J-M (2015) Emergence of OXA-48-producing Escherichia coli clone ST38 in fowl. Antimicrob Agents Chemother 59:745-746

200. Mittal G, Gaind R, Kumar D, Kaushik G, Gupta KB, Verma PK et al (2016) Risk factors for fecal carriage of carbapenemase producing Enterobacteriaceae among intensive care unit patients from a tertiary care center in India. BMC Microbiol 16:138

201. Reuland EA, Al Naiemi N, Kaiser AM, Heck M, Kluytmans JA, Savelkoul PH et al (2016) Prevalence and risk factors for carriage of ESBL-producing Enterobacteriaceae in Amsterdam. J Antimicrob Chemother 71:1076-1082

202. Ruppé E, Armand-Lefèvre L, Estellat C, El-Mniai A, Boussadia Y, Consigny PH et al (2014) Acquisition of carbapenemaseproducing Enterobacteriaceae by healthy travellers to India, France, February 2012 to March 2013. Euro Surveill 10:19

203. Dautzenberg MJD, Ossewaarde JM, de Greeff SC, Troelstra A, Bonten MJM (2016) Risk factors for the acquisition of OXA-48producing Enterobacteriaceae in a hospital outbreak setting: a matched case-control study. J Antimicrob Chemother 71:22732279

204. Swaminathan M, Sharma S, Poliansky Blash S, Patel G, Banach DB, Phillips $M$ et al (2013) Prevalence and risk factors for acquisition of carbapenem-resistant Enterobacteriaceae in the setting of endemicity. Infect Control Hosp Epidemiol 34:809-817

205. Debby BD, Ganor O, Yasmin M, David L, Nathan K, Ilana T et al (2012) Epidemiology of carbapenem resistant Klebsiella pneumoniae colonization in an intensive care unit. Eur J Clin Microbiol Infect Dis 31:1811-1817

206. Zenati K, Touati A, Bakour S, Sahli F, Rolain JM (2016) Characterization of NDM-1- and OXA-23-producing Acinetobacter baumannii isolates from inanimate surfaces in a hospital environment in Algeria. J Hosp Infect 92:19-26

207. Kramer A, Schwebke I, Kampf G (2006) How long do nosocomial pathogens persist on inanimate surfaces? A systematic review. BMC Infect Dis 6:130

208. Lemmen SW, Häfner H, Zolldann D, Stanzel S, Lütticken R (2004) Distribution of multi-resistant Gram-negative versus Gram-positive bacteria in the hospital inanimate environment. J Hosp Infect 56:191-197

209. Vaz-Moreira I, Varela AR, Pereira TV, Fochat RC, Manaia CM (2016) Multidrug resistance in quinolone-resistant Gram-negative 
bacteria isolated from hospital effluent and the municipal wastewater treatment plant. Microb Drug Resist 22:155-163

210. Picão RC, Cardoso JP, Campana EH, Nicoletti AG, Petrolini FV, Assis DM et al (2013) The route of antimicrobial resistance from the hospital effluent to the environment: focus on the occurrence of KPC-producing Aeromonas spp. and Enterobacteriaceae in sewage. Diagn Microbiol Infect Dis 76:80-85

211. Galler H, Feierl G, Petternel C, Reinthaler FF, Haas D, Grisold AJ et al (2014) KPC-2 and OXA-48 carbapenemase-harbouring Enterobacteriaceae detected in an Austrian wastewater treatment plant. Clin Microbiol Infect 20:O132-O134

212. Nasri E, Subirats J, Sànchez-Melsió A, Mansour HB, Borrego CM, Balcázar JL (2017) Abundance of carbapenemase genes (blaKPC, blaNDM and blaOXA-48) in wastewater effluents from Tunisian hospitals. Environ Pollut 229:371-374

213. Tafoukt R, Touati A, Leangapichart T, Bakour S, Rolain J-M (2017) Characterization of OXA-48-like-producing Enterobacteriaceae isolated from river water in Algeria. Water Res 120:185-189

214. Guardabassi L, Schwarz S, Lloyd DH (2004) Pet animals as reservoirs of antimicrobial-resistant bacteria. J Antimicrob Chemother 54:321-332

215. Scott Weese J (2008) Antimicrobial resistance in companion animals. Anim Health Res Rev 9:169-176

216. Abraham S, Wong HS, Turnidge J, Johnson JR, Trott DJ (2014) Carbapenemase-producing bacteria in companion animals: a public health concern on the horizon. J Antimicrob Chemother 69: $1155-1157$

217. Trott D (2013) $\beta$-lactam resistance in Gram-negative pathogens isolated from animals. Curr Pharm Des 19:239-249

218. Schmiedel J, Falgenhauer L, Domann E, Bauerfeind R, PrengerBerninghoff E, Imirzalioglu $C$ et al (2014) Multiresistant extended-spectrum $\beta$-lactamase-producing Enterobacteriaceae from humans, companion animals and horses in central Hesse, Germany. BMC Microbiol 14:187

219. Melo LC, Boisson MNG, Saras E, Médaille C, Boulouis H-J, Madec J-Y et al (2017) OXA-48-producing ST372 Escherichia coli in a French dog. J Antimicrob Chemother 72:1256-1258

220. da Costa PM, Loureiro L, Matos AJF (2013) Transfer of multidrug-resistant bacteria between intermingled ecological niches: The interface between humans, animals and the environment. Int J Environ Res Public Health 10:278-294

221. Aarestrup FM (2015) The livestock reservoir for antimicrobial resistance: a personal view on changing patterns of risks, effects of interventions and the way forward. Philos Trans R Soc Lond Ser B Biol Sci 370:20140085

222. Braun SD, Ahmed MFE, El-Adawy H, Hotzel H, Engelmann I, Weiß D et al (2016) Surveillance of extended-spectrum betalactamase-producing Escherichia coli in dairy cattle farms in the Nile Delta, Egypt. Front Microbiol 7:1020

223. Fischer J, Rodríguez I, Schmoger S, Friese A, Roesler U, Helmuth $\mathrm{R}$ et al (2012) Escherichia coli producing VIM-1 carbapenemase isolated on a pig farm. J Antimicrob Chemother 67:1793-1795

224. Fischer J, Rodríguez I, Schmoger S, Friese A, Roesler U, Helmuth $\mathrm{R}$ et al (2013) Salmonella enterica subsp. enterica producing VIM-1 carbapenemase isolated from livestock farms. J Antimicrob Chemother 68:478-480

225. Pulss S, Semmler T, Prenger-Berninghoff E, Bauerfeind R, Ewers C (2017) First report of an Escherichia coli strain from swine carrying an OXA-181 carbapenemase and the colistin resistance determinant MCR-1. Int J Antimicrob Agents 50:232-236

226. Hamza E, Dorgham SM, Hamza DA (2016) Carbapenemaseproducing Klebsiella pneumoniae in broiler poultry farming in Egypt. J Glob Antimicrob Resist 7:8-10
227. Dahms C, Hübner N-O, Kossow A, Mellmann A, Dittmann K, Kramer A (2015) Occurrence of ESBL-producing Escherichia coli in livestock and farm workers in Mecklenburg-Western Pomerania, Germany. PLoS One 10:e0143326

228. Poirel L, Berçot B, Millemann Y, Bonnin RA, Pannaux G, Nordmann P (2012) Carbapenemase-producing Acinetobacter spp. in cattle, France. Emerg Infect Dis 18:523-525

229. Reuland EA, Al Naiemi N, Raadsen SA, Savelkoul PH, Kluytmans JA, Vandenbroucke-Grauls CM (2014) Prevalence of ESBL-producing Enterobacteriaceae in raw vegetables. Eur J Clin Microbiol Infect Dis 33:1843-1846

230. Madec J-Y, Haenni M, Nordmann P, Poirel L (2017) ESBL/ AmpC- and carbapenemase-producing Enterobacteriaceae in animals: a threat for humans? Clin Microbiol Infect. https://doi.org/ 10.1016/j.cmi.2017.01.013

231. Abdallah HM, Reuland EA, Wintermans BB, al Naiemi N, Koek A, Abdelwahab AM et al (2015) Extended-spectrum $\beta$-lactamases and/or carbapenemases-producing Enterobacteriaceae isolated from retail chicken meat in Zagazig, Egypt. PLoS One 10: e0136052

232. Janecko N, Martz S-L, Avery BP, Daignault D, Desruisseau A, Boyd D et al (2016) Carbapenem-resistant Enterobacter spp. in retail seafood imported from Southeast Asia to Canada. Emerg Infect Dis 22:1675-1677

233. Yaici L, Haenni M, Saras E, Boudehouche W, Touati A, Madec JY (2016) blaNDM-5-carrying IncX3 plasmid in Escherichia coli ST1284 isolated from raw milk collected in a dairy farm in Algeria. J Antimicrob Chemother 71:2671-2672

234. Touati A, Mairi A, Baloul Y, Lalaoui R, Bakour S, Thighilt L et al (2017) First detection of Klebsiella pneumoniae producing OXA48 in fresh vegetables from Béjaïa city, Algeria. J Glob Antimicrob Resist 29:17-18

235. Rouffaer LO, Haesebrouck F, Martel A (2014) Extended-spectrum $\beta$-lactamase-producing Enterobacteriaceae isolated from feces of Falconidae, Accipitridae, and Laridae in bird rescue centers in Belgium. J Wildl Dis 50:957-960

236. Bonnedahl J, Hernandez J, Stedt J, Waldenström J, Olsen B, Drobni M (2014) Extended-spectrum $\beta$-lactamases in Escherichia coli and Klebsiella pneumoniae in gulls, Alaska, USA. Emerg Infect Dis 20:897-899

237. Dolejska M, Masarikova M, Dobiasova H, Jamborova I, Karpiskova R, Havlicek M et al (2016) High prevalence of Salmonella and IMP-4-producing Enterobacteriaceae in the silver gull on Five Islands, Australia. J Antimicrob Chemother 71: 63-70

238. Caron A, Cappelle J, Cumming GS, de Garine-Wichatitsky M, Gaidet N (2015) Bridge hosts, a missing link for disease ecology in multi-host systems. Vet Res 46:83

239. Bonnedahl J, Järhult JD (2014) Antibiotic resistance in wild birds. Ups J Med Sci 119:113-116

240. Bachiri T, Bakour S, Lalaoui R, Belkebla N, Allouache M, Rolain $\mathrm{JM}$ et al (2017) Occurrence of carbapenemase-producing Enterobacteriaceae isolates in the Wildlife: First report of OXA48 in wild boars in Algeria. Microb Drug Resist. https://doi.org/ 10.1089/mdr.2016.0323

241. Solà-Ginés M, González-López JJ, Cameron-Veas K, PiedraCarrasco N, Cerdà-Cuéllar M, Migura-Garcia L (2015) Houseflies (Musca domestica) as vectors for extended-spectrum $\beta$-lactamase-producing Escherichia coli on Spanish broiler farms. Appl Environ Microbiol 81:3604-3611

242. Davari B, Kalantar E, Zahirnia A, Moosa-Kazemi S (2010) Frequency of resistance and susceptible bacteria isolated from houseflies. Iran J Arthropod-Borne Dis 4:50-55 